\title{
ANIMA EST
}

\section{A Thesis Presented to the Faculty \\ of \\ IICSE University \\ Wilmington, DE 19899, U.S.A.}

\section{In Partial Fulfillment}

of the Requirements for the Degree of

Master of Philosophy

\author{
By \\ Marcia R. Pinheiro \\ June 2015
}

ABC Research Alert, Vol 3, No 1 (2015) 
CERTIFICATION OF APPROVAL

Anima Est

by

Marcia R. Pinheiro 


\section{Acknowledgements}

God and the Spiritist Church, St. John's, have helped us greatly.

Hamish was also a huge source of inspiration. 
Acknowledgements. i

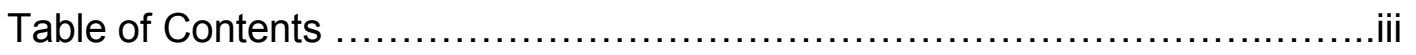

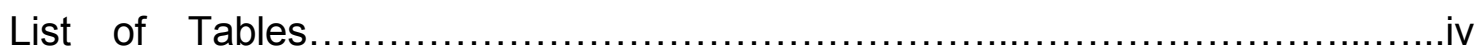

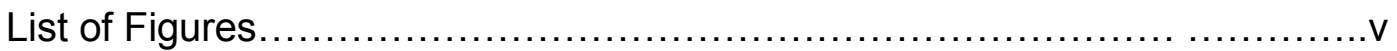

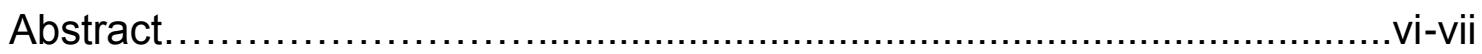

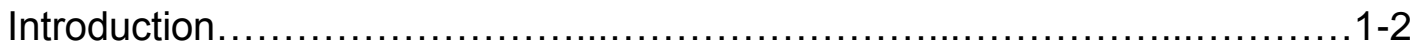

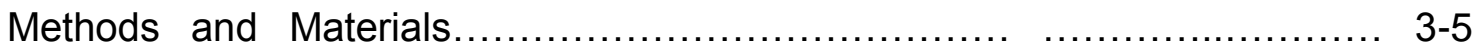

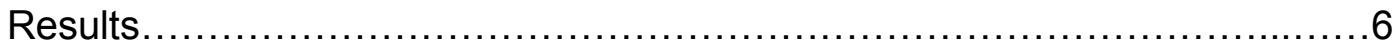

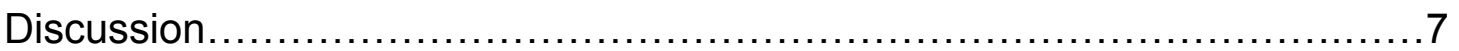

1. The Human Psyche and What is on during Sleep or Hypnosis.................

1.1 Freudian Divisions (id, superego, and ego) and their Extensions..............

1.1.1 When We Are Sleeping, the Id is off...................................12

1.1.2 When We Are Sleeping, the Superego is off.......................... 13

1.1.3 When we are sleeping, the ego is off.................................... 14

1.1.4 Neither the Extended Elements of Freud nor the Original Elements Are on when We Are Sleeping .............................................. 15

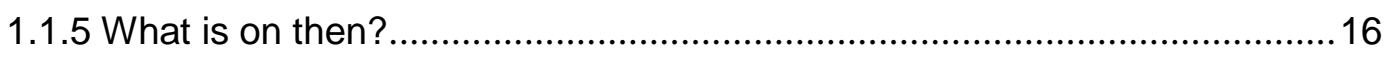

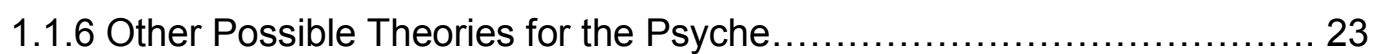

1.1.7 We Are not Ourselves when We Sleep, so Let's Act Coherently................32

2. Soul/Spirit and Sleep....................................................... 41

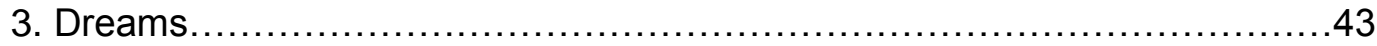

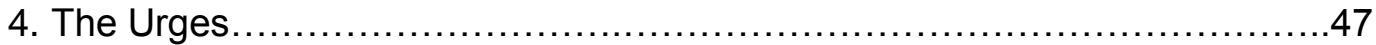

5. The Best Possible Explanation and Science............................... 49

6. On Love and Modifying the Person We Claim to Love against Their Will.......51

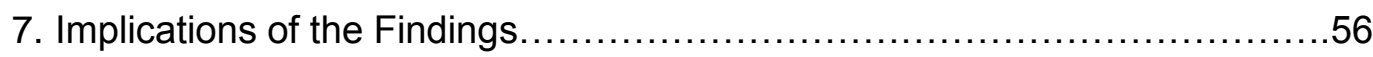

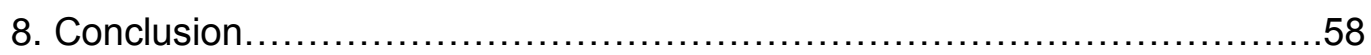

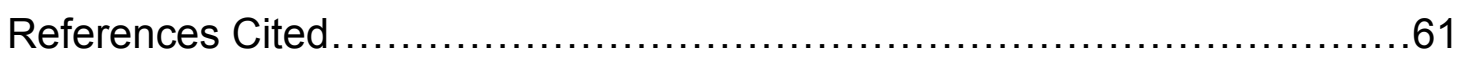

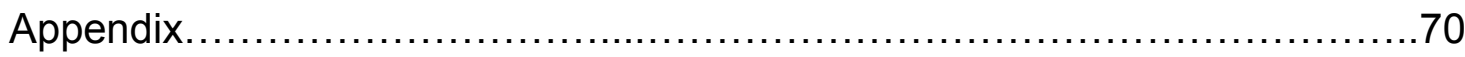




\section{LIST OF TABLES}

TABLE

PAGE

1. Energy Expenditures $x$ Activities

31 


\section{LIST OF FIGURES}

TABLE

1. Jung's Psyche Model
PAGE

17 


\section{ABSTRACT}

Our investigative question is what part of the human psyche is active when we are sleeping.

We use the single-counter-example method, extracted from Classical Logic, to prove that it could not be the case that one of our existing models for the human psyche could explain the human sleep.

The models of the human psyche that we consider are the Freudian, the Jungian, and our own (Pinheiro, 2014a).

By proving that no known part could be active whilst we sleep, and we prove all by presenting known facts, we reach the conclusion that we need a new model of psyche to account for the entire complexity of our beings.

We associate sleep with dreams. Upon discussing the human dreams in more details, we end up applying the principles of the inference to the best explanation to explain the human dreams by means of references to the spiritual world.

That makes us think about how the spiritists would describe our psyche, and we then present a new model. The new model is obviously a fruit of speculation.

This time, the model involves all Freudian elements, our extensional elements, body, and soul. We use the synthetic method to construct our new model.

Since our sleep time is so important, to the point of obliging us to build a new model for the human psyche, we worry about protecting it.

We then use studies on the impact of noise on humans to talk about how bad the consequences of having a person speaking to us during sleep are. This trivially extends to people that are in hypnotic state.

We try to make a case against hypnosis and interference with the sleep of human beings by referring to health, spiritual, and world consequences. 
Our main result is then a new model for the human psyche, and this time a model that has to do with what is beyond what has already been formally acknowledged by us.

A secondary result is that we should not allow people to hypnotize others or to speak to them as they sleep.

Our conclusions are that there is definitely something beyond our rationality that happens during our sleep time and this something has not been identified by Freud, Jung or us this far. Besides, that we should not allow people to hypnotize others or speak to them as they sleep. 


\section{INTRODUCTION}

Almost everyone who writes about the human psyche mentions the Freudian model somehow. This model contains three instances: id, ego, and superego (Thornton, 2001).

We have used that knowledge to safely draw our own model for the human psyche (Pinheiro, 2014a).

The intentions here are trying to address the main issues associated with hypnosis and conversations during bed time with the sleeping person.

Our concern with the matter has emerged from the popular belief that if one converses with a sleeping or hypnotized subject, then whatever that subject says in that state is more truthful than whatever they could be saying in any other state (see (Rosen, 2012), (Rabogie, 2010), Suelen (2011), and Coco (2013)).

Things are not that simple and speaking to sleeping or half-sleeping subjects is not something that should be tried for several reasons. Some of those reasons will be presented in this thesis.

Some men believe that if they make suggestions to a woman who is half sleeping or sleeping, she will follow those suggestions and that is either fun/exciting/interesting or a means to fix unwanted behavior (Cliff's List, 2013).

What happens, however, is that any interference with a person's sleep may cause lifetime damage to them, and any action of theirs that occurs as a reaction to those suggestions can only be unnatural. Besides, the necessity of modifying the original person can only mean that there is no real love for that person coming from the 
person that tries to modify them or there is no real acceptance of diversity from their end. If there is any love involved, it can only be love for a modified version of the person, not for the person themselves.

Any action that intends to modify the individual against their will, or without their awareness or consent, can only be seen as a psychotic action.

It would be wise replacing those actions, or thoughts of performing those, with hypnotic self-suggestions over that who is trying to modify the other in order to make them accept the idiosyncrasies of the person they worry about or in order to make them learn how to love their partner AS THEY ARE, and therefore how to make of their relationship something healthy.

Notice that what has just been stated regards modifications that are not wanted by the individual, so that we are not referring to the case in which our partner turns to us and asks for our help to change their behavior. That is considered a totally different matter.

We would like to be proving, in this thesis, that:

1) there is no more truth to the discourse of the hypnotized or half-asleep or sleeping person than there is to the fully awake individual;

2) we currently do not have any model for the human psyche that can describe, perfectly well, the human sleep;

3) we could have a spiritists' model for the human psyche;

4) when we sleep, none of the elements of the models we here mention (Freud's, Jung's or Pinheiro's) is on;

5) nobody can claim to love and wish for being believed if they want to modify the other person against their will; and

6) any interference with the sleep of a person is a heinous thing.

We would like to be presenting very logical, consistent, and coherent argumentation to prove our points. 
We make use of tables that describe the amount of energy spent per human activity. These tables have been produced by the Harvard University, Faculty of Medicine, the Georgia Institute of Technology, College of Computing, and Proserve Technology. This would be simple data analysis.

We then apply the Arquimedian Principle (Encyclopaedia, 2015), which says that the weight of the displaced portion of the fluid is equivalent to the magnitude of the buoyant force to produce a theory regarding our dreams. They would have to be coming from outside of us because all the activities that could generate them could not be happening due to a logical reasoning that is similar to that that led to the Arquimedian Principle: The dream is lifting us and we then would have to have a compatible level of energy expenditure or of splash, that is, of calories leaving us, but we do not have such a thing. The Inference to the Best Explanation (Doyle, 2014) leads us to finally draw our hypothesis: Dreams probably come from spiritual interactions.

As for the arguments opposing people trying to converse with us or trying to extract information from us when we are in a sleeping state (AAPH, 2011), they are formed with basis on the data extracted from: a table that the government of Hong Kong produced (Table 2), a study produced by the World Health Organization (2009), a presentation produced by Franke (2003), and a study produced by the International Labour Organization (1999) at least.

We get the just-mentioned data, perform our logical analysis on it, together with some comparative studies, and infer, through Modus Ponens, that the effects of the noise of the person trying to converse with us would characterize their action as a hazard to our health. 
We also use some studies on dreams (Garfield's, Valli's and Revonsuo's at least) to determine how many dreams an average human being has in average per normal night of sleep and talk about the effects of changing the dreams of others artificially, so say through oral suggestion during their sleep or waking them up. One of the points we make in a subtle manner, so that this is all empirical, is that a person may commit suicide because of our interference with their sleeping patterns or dreams (Minha noticia, 2007).

We make use of the traditional divisions of the human psyche (Jung's and Freud's) plus a modified division (Pinheiro's) to determine what is active, in terms of the human psyche, during a human dream/sleep. This would then be a process that is similar to a literary review and hypothesizing.

When going through this path, we use the false contrapositive method, since we then exhibit one counter-example for each possible association of our dreams/sleep with a layer of the human psyche (considering the mentioned models).

We then hypothesize, as a consequence of using our false contrapositive method, that we actually need a new model for the human psyche, a model that ALSO addresses our dreams.

That is when the Spiritists' Model becomes a possibility.

We introduce this model, which appears as a derivation of isolating some basic wellknown spiritists' beliefs and supporting them with well-known spiritists' literature, and claim that that is one of the so many models that the spiritists could be presenting to us when writing about the human psyche in a serious manner.

We are then making use of synthetic inferences, as a result of applying the analysis, evaluation, and synthesis levels of the Bloom's Taxonomy to our reflections, to draw the new model.

Spiritism is mostly based on empiricism, so that our new model is also based on empiricism.

We draw from widely known historic examples to talk about induction to action and thinking, things like dictatorship. We then make a comparative study involving the 
results gotten for induction to action and thinking and hypnosis. We make analytic inferences about the intentions with such a (heinous) practice based on empirical results that we mention. We here would be using the scientific induction.

Using passive empiricism, that is, the practice of observing real-life cases, we identify a few possible intentions with the practice of talking with a sleeping or half-sleeping subject. One of those intentions would be, for instance, getting the actual truth from them more easily.

We try to prove, by means of using our studies on what would be on during the human sleep, and therefore our synthetic inferences together with the results from our false contrapositive proofs, that the individual is not more of themselves as they sleep, rather the contrary, so that there is obviously less chance, not more, that the truth appears in such a situation.

Another intention could coincide with the stage intentions of hypnosis, which are mostly getting people to do what they do not want to.

That is when we draw an analogy between hypnosis, speaking to a sleeping or halfsleeping person, and dictatorship, and we then use the arguments against dictatorship to mark these practices as heinous. We here use synthetic inferences and comparative studies. 


\section{RESULTS}

In this thesis, we:

1) Prove that it is not possible to describe the human sleep by means of any of our preferred psyche models (Jung's, Freud's, and Pinheiro's);

2) Suggest the creation of a new model to address this issue: The Spiritists' Model of the Human Psyche;

3) Prove that there is no more truth to the discourse of a sleeping or half-sleeping person than there is to their discourse when they are fully awake;

4) Prove that speaking to a sleeping subject or trying to is a health hazard and may bring even death to the subject. In terms of society, even wars may occur as a consequence;

5) Make an association between manipulation of the individual via hypnotic or sleep-time suggestions and dictatorial processes of manipulation, and therefore condemn, based on historic arguments, the procedures of hypnosis and of interference in general with the human sleep;

6) Prove that the human dreams must be connected to spiritual activities;

7) Subtly insinuate that more investment in studies about energy expenditure may return meaningful scientific progresses never imagined before, such as those we seem to have gotten; and

8) Suggest that people with damaged front part of the brain may dream and it is a problem with the equipment and the tests we are running this far that leads us to say that they do not dream. 


\section{DISCUSSION}

\section{The Human Psyche and What is on during Sleep or Hypnosis}

\subsection{Freudian Divisions (id, superego, and ego) and their Extensions}

There is no better mathematical way to describe the Freudian human psyche in what comes to decisional processes than

$$
\text { ID + SUPEREGO + EGO = Decision. }
$$

From a close-to-machine perspective, human instinct will crave for something and will then claim that something as a consequence of craving for it. The superego will then help us judge suitability by giving us its no or yes. The result will be the conscious action or decision, which is what forms the ego or, ultimately, the essence of the individual.

We can then see the mathematical equation as a sum of contributions, so that the values we use to replace the words id, superego, and ego will be parcels of a sum that will determine our decision, and this equation could actually be rewritten in these terms and we could then add a variable, $x$, to replace the possible decision we are analyzing.

\section{$I D(x)+\operatorname{SUPEREGO}(x)+E G O(x)=A C T I O N$, where action is a YES TO THE POSSIBLE DECISION whenever the sum is strong and a NO whenever the sum is weak.}

The id seems to be a common place: All humans seem to have the same instinctive calls.

Starving people, for instance, will feel like stealing the food of others if they do not 
have anything to eat and other people are eating in front of them.

This is then a manifestation of the id. In this case, it is a manifestation of the eating instinct.

Another example is the survival instinct. This instinct is uncontrollable: When someone tries to strangle us, regardless of how much we consciously wish for dying, we will fight for our life to the best that we can.

By here we could write a set of logical instructions to better explain what is going on. See:

\section{Situation 1}

Survival Instinct (ID) + I want to die (EGO) + You shouldn't destroy/Thou shall not kill $($ SUPEREGO) $=$ I will fight to stop the strangulation (decision 1$)$

Yes, I will do the action $=1-1+1$, since ID (I will fight to stop the strangulation) $=$ $100 \%=1$, EGO (I will fight to stop the strangulation) $=-100 \%=-1$, and SUPEREGO (I will fight to stop the strangulation) $=100 \%=1$.

We notice here that it is definitely the case that Mathematics does not apply to real life with perfection, and this is a point we keep on reinforcing (Pinheiro, 2013): The moral orders (superego) are generally weaker than the instinctive calls, so that we perhaps should have used a 0.5 on that parcel instead of 1 . The Mathematics is used here more like an illustration, so that there is an alternative path to understanding and communication. It is definitely not to be taken seriously to the point of thinking that we can rely on this equation to perfectly describe the decisional processes of humans.

\section{Situation 2}

Survival Instinct (ID) + I want to die (EGO) + Dying is good, you will get 12 virgins 
$($ SUPEREGO) $=$ I will not really fight to stop the strangulation (decision 2)

Yes, I will do the action $=-1+1+1$, since ID (I will not really fight to stop the strangulation) $=-100 \%=-1$, EGO (I will not really fight to stop the strangulation) $=$ $100 \%=1$, and SUPEREGO (I will not really fight to stop the strangulation) $=100 \%=$ 1.

Decision 2 is not something that a normal human being can do, so that this decision equates the previous decision for practical purposes. Yet, the reason for the equality has nothing to do with the human psyche: It has to do with our biological systems and other alike things. There could be a human being whose muscles would not involuntarily move to stop the strangulation, it is possible. This human could then be the person whose decisional processes we here have described.

The superego is the accelerator or the brake of the id.

\section{Situation 3}

Person $X$ feels like killing subject $Y$, but they ALWAYS comply with the laws, just like a machine would. Because their superego will jump in and say stop by pushing the brake to the lowest position as quickly as possible, the equation would return

Killing instinct (ID) + I want to kill $Y(E G O)+$ The law is all that matters (SUPEREGO)

$$
\text { = I will not kill } Y \text { (decision 3) }
$$

No, I will NOT do the action $=1+1-2$, since ID $(I$ will kill $Y)=100 \%=1$, EGO (I will kill $Y)=100 \%=1$, and SUPEREGO $(I$ will kill $Y)=200 \%=2$.

The all that matters that accompanied law in the paradigms of the individual under analysis made us give $200 \%$ to morality here.

Once more, the mathematical description can be nothing but inaccurate. It is just an illustration to provide us with an alternative path to understanding, and, therefore, to 
communication.

\section{Situation 4}

Person $X$ feels like killing subject $Y$, and they are serial killers, so that they kill just like a machine would. Because their superego will jump in and say do by pushing the accelerator to the lowest position as quickly as possible, the equation would return

Killing instinct $(\mathrm{ID})+$ I want to kill $Y(\mathrm{EGO})+$ Killing is great $(\mathrm{SUPEREGO})=$ I will kill $Y($ decision 4)

Yes, I will do the action $=1+1+1$, since ID $(I$ will kill $Y)=100 \%=1$, EGO (I will kill $Y$ ) $=100 \%=1$, and SUPEREGO $(I$ will kill $Y)=100 \%=1$.

In case one believes in spiritual life, one may wish for calling these abstract world items body, soul and personal filter. This way, the id would be called body, the superego would be called spirit, or soul, and the ego would be called personal filter.

Krashen talks about affective filters in his work (Schutz, 2014):

the Affective Filter hypothesis embodies Krashen's view that a number of affective variables play a facilitative, but non-casual, role in second language acquisition. These variables include: motivation, self-confidence and anxiety. Krashen claims that learners with high motivation, selfconfidence, a good self-image, and a low level of anxiety are better equipped for success in second language acquisition. Low motivation, low self-esteem, and debilitating anxiety can combine to raise the affective filter and form a mental block that prevents comprehensible input from being used for acquisition. In other words, when the filter is up it impedes language acquisition. On the other hand, positive affect is necessary, but not sufficient on its own, for acquisition to take place.

We talk about personal filters. The affective filter would be part of the personal filter of 
each one of us. It is just that a personal filter would also contain other types of filters, what we could call subfilters. One of them would be the rational filter, so a filter that would contain our morality, for instance.

Trivially, our equation is not always true: It can model, with a lot of inaccuracy, the instantaneous decision processes we go through in life, but it cannot model our decisions in general.

Sometimes, we decide things because of theories, say when we are solving a problem in Mathematics. We actually may not have any id or superego pressures when we do that.

Suppose we are just copying the solution of someone else. At that very moment, we may be deciding things regarding the devices we use, say a pen, but we are probably not thinking as we write: Even though we have made decisions about some elements involved in our actions, we are not making any decision as we repeat the process of copying. It is then as if we have included the order copy in our id in a temporary manner, just for the purposes of getting through that problem. This instruction will not remain stored in our extended id (Pinheiro, 2014a), different from the example with the telephone call that we mention in (Pinheiro, 2014a).

We then are actually adding a few more elements to our model. These elements could perhaps be told to be inside of the previously mentioned elements, however, forming perhaps a subdivision.

We now would have temporary and permanent members in the set forming the difference between the id, properly said (as conceived by Freud), and its extended version.

If we now update our equation to adapt to the new additions, we have:

$$
\text { EXTENDED ID + EXTENDED SUPEREGO + EXTENDED EGO = Decision }
$$




\subsubsection{When We Are Sleeping, the Id is off}

Roberts (1998) gives us Freud's words:

Freud said that the ego stands for reason and good sense while the id stands for untamed passions (Freud, 1933).

We have changed the theory of several well-known researchers by claiming to know what they said when we did not know what they actually said. That is obviously how we ended up saying that a person has too much ego when they see themselves as someone who can never fail, for instance. It is obviously the case that someone who thinks that they can never fail cannot, in what regards this particular judgement, which says that they cannot ever fail, be told to have good sense. We have, therefore, changed the Freudian definition of ego, perhaps refining it, in such a way that it definitely does not mean reason and good sense anymore, but our wishes for ourselves, or our thinking in what regards ourselves, and wishes and thinking that are not of moral or universal order.

See, for instance, the following extract, which is part of Psychology Today (Sichel, 2009):

On the one side too much ego prevents humility and too little ego prevents confidence. Arrogance is the opposite of humility and excessive selfimportance is synonymous with what's referred to as an oversized ego. An out of control ego can hurt you in any area of your life. Ego can be helpful to men in business and in love, but when a man's ego is out control, he'll fail in both areas of life.

When we sleep, our id is turned off. Material evidence of such is given by simple examples. For instance, Piaget has studied babies ( 0 to 6 weeks of age) and has described what could be called grabbing instinct (grasping reflex (McLeod, 2009)) of a baby (American Community Corrections Institute, 2003), which is that instinct of simply holding whatever comes to their hands. That would be seen as an uncontrollable, or involuntary, hand movement of the baby that happens, for instance, because of the presence of an object in their hand. 
However, when they sleep, such an instinctive movement does not occur.

When we beat ourselves because we think that there is a mosquito biting us, we also think, most of the time, that that was an involuntary or uncontrollable action.

However, the person may get covered by mosquito bites as they sleep without ever moving.

This is then a final proof that the id is turned off when we sleep.

\subsubsection{When We Are Sleeping, the Superego is off}

Notice that if we can prove, with examples that be universally accepted, that both the superego and the ego are also turned off, then we have proven that our entire psyche is not present as we sleep, so that we cannot possibly be ourselves during that time.

On the other hand, we will also have proven that the nature of the relationship mind $\mathbf{x}$ actions of ours is unknown by Psychology and Psychiatry in what regards our sleep, since, for both, the human psyche resumes to those three instances.

The superego is an inhibitor or a contributor to the id's choice strength.

The fight for survival is instinctive in nature, as mentioned before.

Yet, some people suffer from somnambulism and will die walking through windows when they are sleeping, for instance, not only not realizing the danger, but going through the fall also without waking up at least sometimes ((CGN, 2011) and (Netcina, 2013)).

Those people are not in an id's process in that instance because they have never intended to kill themselves (Minha noticia, 2007). They are simply hallucinated because of their own dreams and they imagine that they are doing something else, 
just like it happens during hypnosis.

Hypnosis induces the person to sleep, but not to sleep deeply: It induces the person to an intermediary state between being awake and sleeping deeply, yet to a sleeping state, if ever well done (AAPH, 2011).

What happens is that, under these conditions, the person will perform even acts that they feel repulsion for upon suggestion of the hypnotherapist, and this is all universally agreed knowledge, for it is not missing public demonstrations of the power of hypnosis, of even subliminal hypnosis, or manipulation of the human activity by non-consciously-wanted-third-party's-actions-received impact in the human brains.

As simplest known example, we have the experimentation with Coke, in which a few theater attendees have been subjected to a series of subliminal images connected to Coke, none ever detected by those attendees. By the end of the screening, a very large group of those attendees would always purchase Coke, even though they had never intended to do that before watching the movie (Lopes, 2011).

Therefore, the superego of those attendees was turned off as they received those images and purchased Coke in the same way that the superego of the somnambulistic person who has died while sleeping was.

\subsubsection{When we are sleeping, the ego is off}

We can use the same examples, somnambulism and Coke, to argue that the ego is also not on while we sleep.

Basically, the somnambulistic we have mentioned did not want to kill themselves, so that both id and ego would be saying DO NOT JUMP, for instance, if they COULD SPEAK.

We could also have a case of a person who actually never liked Coke but, in the end of that movie, they will buy Coke because of both the subliminal work and peer 
pressure.

Both their id and their ego would be saying DO NOT BUY in this case.

\subsubsection{Neither the Extended Elements of Freud nor the Original Elements Are on when We Are Sleeping}

The extended elements still have the same behavior as the original elements and also the same functions. In this case, they could not possibly be on whilst we are sleeping.

To prove that they are the same in what comes to behavior, functions, and strength, we can consider the example of the lunch bell.

Suppose a human being is in the same place every day at lunch time and, invariably, at lunch time, a bell rings. Suppose that they are then invariably served a meal by someone else when the bell rings.

With time, their mouth will salivate and prepare itself to receive food when the bell rings. Their stomach will also have the same behavior it would have when anticipating food normally (without the bell).

We here then have a case of extended id once more.

What difference there is, in terms of their mouth and stomach, between seeing food when it is time to eat and listening to the bell ringing?

With time, none.

The somnambulistic could have been trained to have an ID reaction to the window touch, for instance. In this case, their extended id would have saved them.

Assuming that no such a training took place, given the results, and, therefore, assuming that the individual was under normal conditions, then there was no 
interference of the possible extended elements either.

We must, however, consider ALSO the situation in which the individual has been subjected to such a training, for the point is that there is no way any extensional element could be present either.

Samurai movies talk about the possibility of being trained to the point of sensing human activity around us during sleep and being able to react in a timely manner.

We must, however, understand that, in this case, the person is not having a normal session of sleep. Their sleep has been shaped to conform to the declared needs, so that they cannot, possibly, keep their minds in the same state a normal person would whilst sleeping, and, therefore, we are not talking about normal sleep here, but modified sleep.

Our theory, however, aims at modeling what is usual in human kind. It is a model, not the only possible model or the model of everyone's psyche. It is the model of the average human being.

\subsubsection{What is on then?}

This way, who are we when we sleep?

We, as human beings, have been psychologically and psychiatrically described as a result of the sum of the superego, ego, and id.

All those elements present value zero in our equation.

Hypnosis is sleeping to a certain degree, so that we all know that the person is a physical entity commanded by others, or passive of being commanded by others, whenever they are at that level of the sleeping process. Therefore, they equate a robot or a dumb computer terminal.

And what thing would be a person who is sleeping in deep sleep? 
People usually dream. Garfield (1977) wrote that we have an average of three dreams per night of sleep after taking careful note of her dreams for a whole year during her PhD.

Valli \& Revonsuo (2009) also assume that we have an average of three dreams (3.3) per night, and their results came from studies about a group of students, not from studying themselves their own dreams.

Where do those dreams come from?

Dreams seem to only come when we are in deep sleep, what means that we will be exhibiting REM when we dream, as mentioned by Patricia in her book (1977).

Our eyes are then seeing inside of our heads, and that is why they move like that, more than likely. As an alternative to seeing things, perhaps even inside of the skin covering our eyes, as in a theater, we have that we try to see those images with our eyes because we are used to that and get desperate trying and that is the reason as to why the eyes move so frantically.

In any hypothesis, dreaming cannot be an activity we perform because we have to be in a static situation, biologically speaking, that be equivalent to that of the hibernating bear (National, 2014).

If it were activity, however, we would be more tired when we wake up and this inference seems to be something logical, deriving from simple premises.

Starner (1996) published a paper containing the following table:

Table 2 Human energy expenditures for selected activities (derived from Reference 3)

$\begin{array}{lcr}\text { Activity } & \text { Kilocal/hr } & \text { Watts } \\ \text { Sleeping } & 70 & 81 \\ \text { Lying quietly } & 80 & 93\end{array}$




$\begin{array}{lcr}\text { Sitting } & 100 & 116 \\ \text { Standing at ease } & 110 & 128 \\ \text { Conversation } & 110 & 128 \\ \text { Eating a meal } & 110 & 128 \\ \text { Strolling } & 140 & 163 \\ \text { Driving a car } & 140 & 163 \\ \text { Playing violin or piano } & 140 & 163 \\ \text { Housekeeping } & 150 & 175 \\ \text { Carpentry } & 230 & 268 \\ \text { Hiking, 4 mph } & 350 & 407 \\ \text { Swimming } & 500 & 582 \\ \text { Mountain climbing } & 600 & 698 \\ \text { Long-distance running } & 900 & 1048 \\ \text { Sprinting } & 1400 & 1630\end{array}$

Table 1: Energy Expenditures x Activities

We notice that sleeping burns calories, but burns fewer calories than any of the other activities on the list.

The closest activity, in calories, would be lying quietly, but this is obviously very similar to sleeping.

We have $43.2 \%$ (app.) more in electricity and $42.86 \%$ (app.) in calories consumed when we are awake and sitting than when we are sleeping according to our table.

When we converse, we obviously eventually also imagine things. In this case, we have a positive difference of $58.02 \%$ (app.) more in electricity and $57.14 \%$ (app.) more in calories if we consider sleeping in contrast.

Notice that this table does not tell us how this conversing took place (would people be lying down, for instance, to make it all more compatible?).

We assume, however, that people were lying down. 
The Harvard University (2000) gives us a table involving calories and activities. They have considered people of three different weights in their studies $(125,155$, and 185 pounds).

When the person is reading and sitting, a consumption of 34,42 , and 50 calories has been verified.

Sitting and reading are passive activities, in principle. The type of material that they read has not been considered in this study, yet that would be priceless information, since we have to use the upper levels of the Bloom's Taxonomy when we read Science and we are scientists, for instance, if the text is of our interest.

A person who is sleeping, according to them, would consume 19, 23, and 28 calories instead.

We then notice that it is almost half the amount of calories needed to sit and read.

Watching TV gets 23,28 , and 33.

We notice that this is more than sleeping and less than reading and sitting.

Notice that we do not interfere with whatever is going on in the TV set, and we are also not asked to think most of the time. Most of the people on earth would agree that watching TV is a completely passive activity almost all the time.

Notwithstanding, we are making an effort to see the image and make sense of all, also to hear the sound, if we can hear.

We assume that the people mentioned by them (Harvard, 2000) did not have sight or hearing problems.

When we read, we do not have to listen. We also do not have to adapt our eyes and put things together in terms of images and sounds. 
In compensation, we have to concentrate on the printed words and associate them with knowledge about the lexicon, culture, and others.

When we watch TV, the context is given to us. The lexicon is forgotten because we can infer things most of the time from seeing the image or we do not care about particular words if we can make sense of the whole.

The attention needed to read a book is of the type dedicated and focused, what usually makes our forefront frown, for instance. The attention needed to watch TV is of the type divided and relaxed, since lots of people on earth would even do something else as they watch TV.

The positive difference to the side of reading must then have to do with focus, dedicated attention, and upper levels of the Bloom's Taxonomy, therefore of brain activity.

Our body is relaxed in all activities we compare now, but should be tenser when we read.

Tension is known to burn calories, so much so that some people die from it.

We then attribute the high score of calories of reading with sitting to the use of the superior levels of our brain plus tensional states of our body.

There is also a positive difference, even though small, to the side of TV, when sleeping is considered.

That has to be because we are doing something that we do not do whilst sleeping when we watch TV.

We sit to watch TV, for instance.

We notice that sitting consumes $25 \%$ more calories than lying quietly whilst sitting (Starner, 1996). 
That gives us almost exactly the difference we have between watching TV and sleeping in the study performed by Harvard.

There is then a non-negligible chance that we do almost the same thing when we watch TV and when we sleep. Notwithstanding, we must acknowledge that there is room for more effort when we watch TV (we actually get $21 \%, 22 \%$, and $18 \%$ more of difference, so that we get from 3 to 7 percentual points to associate with some other extra thing we would be doing whilst watching TV).

Proserve (2013) lets us know that we can burn anything between 101 and 184, in terms of calories, when watching a scary movie.

From the $10^{\text {th }}$ to the $9^{\text {th }}$ movie on their list there is a distance of 6 calories (107 to 101). The ratio returns about 6 percentual points of difference $(1.0594$ if rounded to the fourth decimal place).

We can then theorize that this is what makes the difference between watching TV and dreaming: The amount of involvement of ours. This can only have to do with how much of our brain is actually allowing us to react to the images, we reckon.

Dreaming would be more passive than watching TV, and therefore we would have less allowance for reaction.

This is evidence to the side of having the images inserted in our heads by something or someone else, since if we had to actively create them, then our consumption of energy would be superior.

Notice that refinish furniture, which is regarded as an inferior intellectual activity, takes 135,167 , and 200 units. This is way more than what we had for sleeping, TV, and reading.

This is a creative activity because it is an art, right? 
Yet, it demands a low level of creativity, since it is just fixing.

One could safely say that it would be located in the lowest levels of creativity.

In this case, we could not possibly create as we sleep.

We could be sitting as we refinish furniture, and again we do not have enough details, but, even so, we can tell, because of the figures involved (about 80 times more than sleeping or TV), that we cannot possibly be creating whilst we sleep.

In this case, the most we could be doing is reacting to stimuli.

We know of people who cry and speak during the bed time, so that reacting is something we know happens for sure to some during sleep (Thiedke, 2001).

Notwithstanding, we could never be creating.

Because of the sure existence of the premonitory dreams (Freud, p. 237, 1900), we could not be recollecting and reorganizing facts all the time whilst sleeping either.

When we are sitting in a class, we frequently have to recall learning and organize things in our heads, but we usually do not create or interfere with whatever is going on. Notice that, in this case, we spend 53, 65, and 78 units, according to Harvard (2001). When we compare with sleeping, even if we add the $20 \%$ of difference because we would be sitting, we notice that it is impossible that we be watching and recollecting or organizing things in our heads.

In this case, all dream content would have to be coming from another source, which is not our body or person, as we know them.

Thus, we do not perform activity and, even so, those images are formed, that is, they manifest themselves in our heads against our will or at least without our consent. 
If we are not spiritualists, we are left with creating another explanation that escapes communion of thought with other beings, alive or dead, who then will either use our matter as we sleep, to perhaps even send us subliminal messages and through that interfere with our lives, or be imagining things and their imagination will find our lines in open state, so that their thoughts will enter us (Welsh, 2011).

In any hypothesis, we are neither resisting that invasion nor actively creating any part of those images.

With this, we have just proven that a human being that is sleeping may be a vehicle of energies, forces or others.

It is then possible that our soul be in charge of our bodies, what may imply harm and/or benefit of involuntary nature to our physical body.

Whatever the thing that is in charge of our bodies during sleep is, it cannot be regarded as ourselves, since we cannot, for instance, not do what we do not want to do during those periods of time.

Because it is not ourselves, either in full or ever, there is no point in conversing about whether what we say during those times is truer or less true than what we say outside of those times (of sleep): That is simply not us.

We would have to be at least id, ego, and superego.

We are only with our persona if we are fully awake, and, therefore, in no hypnotic-like state.

\subsubsection{Other Possible Theories for the Psyche}

Other theories exist that be not that of Freud in terms of psyche.

Kazlev (2013) tells us about the theory of Jung, for instance. 
The Collective Unconscious seems to allow for us to infer that those moments of dreaming could be shared with others, so that the coincidences noticed by researchers in the dreams of a few subjects could not be as accidental as they may seem.

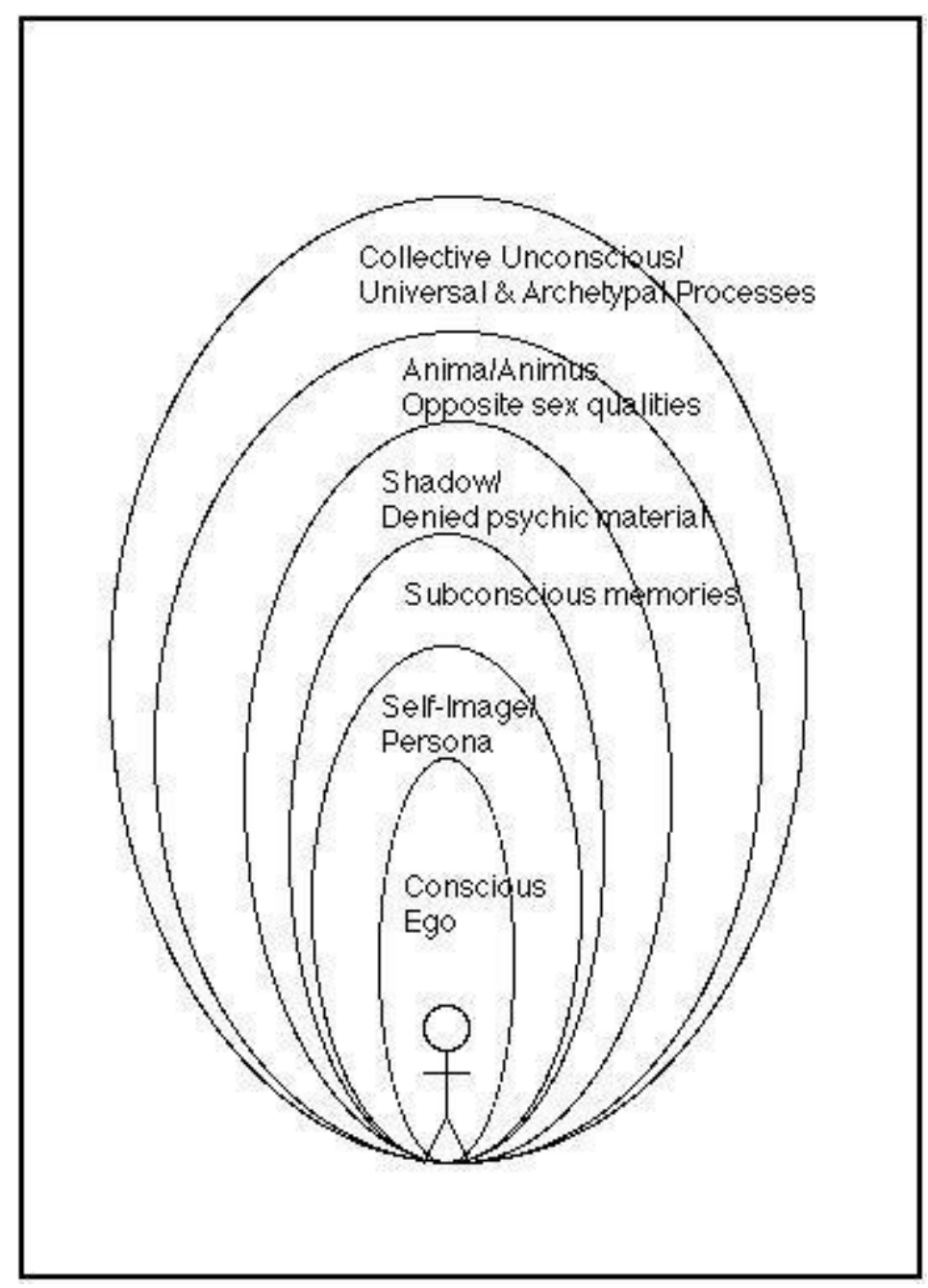

(Kazlev, 2013)

Figure 1: Jung's Psyche Model 
We could not be left with the Anima/Animus because, as we see in the extract below, which originated in Engler (1999), that is the collection of our communions with the opposite gender.

Thus, the anima archetype is the feminine side of the male psyche, and the animus archetype is the masculine side of the female psyche.

The Anima/Animus is actually part of our memory or subconscious then, but we have decided that we cannot be recollecting or organizing things in our heads during sleep. This also does not seem to be a component of actions more than it seems to be a descriptive tag. It seems that this Jungian component could be fully addressed by one of the Freudian elements, since its influence will have to be of one of those types (id, ego or superego) in terms of decisions, and, therefore, actions.

The C. G. Jung Society of Atlanta (1999) tells us that

In 1948 Jung gave a brief lecture on the shadow to the Swiss Society of Practical Psychology. At this time he was in his 70's and had lived through two World Wars and numerous encounters with the shadow in his own personal and professional life. Now he regards the shadow with measured objectivity and great respect. His writing has a sardonic tone, as though he has come to an uneasy stand-off in his negotiations with the enemy. He states that the shadow is one of the three archetypes which has "the most frequent and the most disturbing influence on the ego." (The others are the anima and animus.) It consists of the inferior and "primitive" aspects of the psyche -- those traits which we regard as undesirable, "bad," or sinful. While the shadow is "the most accessible" of the three archetypes and therefore "the easiest to experience," it is "a moral problem that challenges the whole personality." Coming to terms with it requires "considerable moral effort" because we do not want to admit that we ourselves possess the dark qualities we despise. We unconsciously project our shadow outward and see it in others rather than becoming conscious of it in ourselves. 
The shadow could be seen as a shadow of our ego and the own Jung is told to have identified it with Freud's id (Stein, 2013).

In this case, we have already proven that the shadow could not be on when we sleep.

Subconscious memories are obviously those memories that remain in our subconscious and therefore, as Miller (2010) points out, actually in a likely-to-bephysical place of our mind, which is not immediately accessible to us. In any hypothesis, they are memories.

Because in the dreams studied by Patricia Garfield and by quite a few other people they are able to fly, but they certainly do not fly in reality, we know that at least sometimes our sleeping bodies are not formed of subconscious memories.

In Reich (2003), we find the following text:

I dreamed I was flying through the sky, and at the moment that I became aware I was dreaming, my entire perception seemed to expand. The sky widened into a panoramic view, as if suddenly I was unhindered by limited human vision and could see all around me at once. I could see every valley and pathway below me in minute detail, while simultaneously absorbing the blue sky all around.

You know, it's odd, but I'm not certain if I was human or bird or both. I never looked at myself, I was so lost in the sensation of flying. It felt so real! The weight of my limbs, the thrust of the currents of air, the flow and at times restriction, then release. I seemed "me", yet my arms/wings caught the wind like no human hands; I felt so free from earthly/bodily restrictions! Picture me as you like; best might be a woman with wingarms. Half human, half bird--but integrated. 


\begin{abstract}
A fierce, cold mountain wind fluffed my downy feathers, making me aware how fragile and vulnerable I was. I seemed so fragile there--so tiny against that monumental landscape. Yet I felt strong--no doubt or fear or longing, though I was alone, with no mother or father eagle to care for me. Regardless of how fragile I looked, I felt a strong faith in the Unseen. My place there was right, was home, was where I was meant to be. All would be okay.
\end{abstract}

The thing is that this dream could not have come from any piece of the subconscious described by Jung unless we admit the existence of the soul/spirit because the lady would never have flown in her life in the way she described. This way, nothing could have been inside of her memory in those regards, neither in the conscious nor in the unconscious side of her memory; neither in the collective nor in the personal side of her unconscious.

Our dreams, at least sometimes, then, are not formed of memories.

Because there is an underlying organization in the dreams, which can be proven by means of the sequence, the plot, and others, we could not be talking about unconscious material with exclusivity, like things that would then surface, either.

The persona is, according to Hopwood (2006),

a part of the personality which comes into existence for reasons of adaptation or personal convenience'. The origin of the term comes from the mask worn by Greek actors in antiquity and denotes the part of the personality which we show to the world. The persona has been called 'the packaging of the ego' or the ego's public relations person, and is a necessary part of our everyday functioning. One might say that one's social success depends on having a reasonably well-functioning persona, one which is flexible enough to adapt to different situations, and which is a good reflection of the ego qualities which lie behind it. 
However trouble comes when a person is identified with their persona, and everyone will have come across people who cannot leave behind their work persona, such as a teacher who treats everyone as though they were still in primary school, or bossily tells people what to do. Although this is annoying to be with, the more serious part of it is that it may leave major aspects of the personality unrealised, and the individual therefore significantly impoverished. The persona grows out of the need in childhood to adapt to the expectations of parents, teachers and peers, and this may well mean that the persona carries traits of personality which are desirable, leaving the opposite, undesirable traits to form part of the shadow.

The extract,

The shadow can be thought of as a subpersonality who wants what the persona will not allow (Stein, 2013),

makes us understand that the persona acts more or less as a censor of the shadow, which has been associated with the Freudian id. In this case, it should be part of the Freudian superego.

We have already proven that the superego is not on whilst we sleep. Therefore, the persona is not on either.

The self, according to Hopwood (2006),

for Jung comprises the whole of the psyche, including all its potential. It is the organising genius behind the personality, and is responsible for bringing about the best adjustment in each stage of life that circumstances can allow. Crucially, it has a teleological function: it is forward looking, seeking fulfilment. The goal of the Self is wholeness, and Jung called this search for wholeness the process of individuation, the purpose being to develop the organism's fullest potential. 
Again according to Hopwood (2006),

Jung writes: 'By psyche I understand the totality of all psychic processes, conscious as well as unconscious', (CW6 para 797) so we use the term 'psyche' rather than 'mind', since mind is used in common parlance to refer to the aspects of mental functioning which are conscious. Jung maintained that the psyche is a self-regulating system (like the body).

We have already proven that the superego is not on as we sleep, therefore the whole of the psyche, or the self, is not on either.

Our ego, according to Hopwood (2006), is seen by Jung as

the centre of the field of consciousness which contains our conscious awareness of existing and a continuing sense of personal identity. It is the organiser of our thoughts and intuitions, feelings, and sensations, and has access to memories which are not repressed. The ego is the bearer of personality and stands at the junction between the inner and outer worlds.

The Jungian ego could not therefore be present as we sleep either because the word consciousness has been used to define the concept.

According to the same source, Hopwood (2006), we would still have the complexes and the individuation to worry about in terms of Jung.

A complex, according to (C. G. Jung, 2010), is

a collection of images and ideas, clustered round a core derived from one or more archetypes, and characterized by a common emotional tone.

When they come into play (become 'constellated'), complexes contribute to behavior and are marked by affect whether a person is conscious of them or not. 
From what we understand, a person could not make use of complexes when sleeping because it is like watching TV: Not an active thing. Because we do not normally have a decision about our dreams or actions during sleep (Patricia Garfield proposes a method through which we can change a few things in a certain type of dream, called lucid, but this is something atypical and very hard to get (Kellogg, 2005)), the complex could not be coming into play.

From (Jungian, 2013), we read:

A third difficulty comes from the self-knowledge that is part of the process. "Self-knowledge" means becoming conscious of the unconscious: facing our shadow and becoming aware of the reality of our "inner partner," the animus (for women) or the anima (for men).[21] The work of individuation takes us through the "swamplands of the soul"[22] in thenigredo phase mentioned in an earlier essay.[23] While Jung was clear that the unconscious takes to us the attitude we take to it,[24] for most people it takes a while (if it ever happens at all!) to develop a cheerful attitude toward the unconscious.

Now we know that the process of individuation (becoming conscious of the unconscious) is not something that may happen during sleep, so that this is also not on.

All Jungian elements considered, the only elements that we have not considered in the previous analysis, of the Freudian elements, that still could be something in terms of our sleep/dreams, and, more specifically, in terms of the dreams involving flying, would be The Unconscious. The Personal Unconscious would be discarded in what comes to the dreams about things we have not experienced (such as flying) because, according to Encyclopaedia (2004), it is formed of personal experiences.

The Collective Unconscious is supposed to contain archetypes or universal primordial images and ideas only (Encyclopaedia, 2014).

Encyclopaedia (2014) reminds us that the Collective Unconscious is a 
term introduced by psychiatrist Carl Jung to represent a form of the unconscious (that part of the mind containing memories and impulses of which the individual is not aware) common to mankind as a whole and originating in the inherited structure of the brain. It is distinct from the personal unconscious, which arises from the experience of the individual. According to Jung, the collective unconscious contains archetypes, or universal primordial images and ideas.

The personal unconscious is, according to Hopwood (2006),

Everything of which I know, but of which I am not at the moment thinking; everything of which I was once conscious but have now forgotten; everything perceived by my senses, but not noted by my conscious mind; everything which, involuntarily and without paying attention to it, I feel, think, remember, want, and do; all the future things which are taking shape in me and will sometime come to consciousness; all this is the content of the unconscious (CW8, para 382).

Besides these we must include all more or less intentional repressions of painful thought and feelings. I call the sum of these contents the "personal unconscious"(CW8, para 270).

Even if we admit that we might have lived other lives or might have exploited other beings' bodies as we sleep, it is almost impossible to claim that our dreams come from the unconscious because we still would be spending that energy we talked about before to put things together, in the right order, to remember them, and etc.

Wayan (1969) also dreamed of flying without ever having flown with his physical body.

Perhaps Jung was more of a psychoanalyst and Freud was more of a psychiatrist, so that Jung tries to describe our logical processes and Freud tries to describe our actions. 
As a psychiatrist, what worries Freud is obviously fixing behavior, things like people yelling out of the blue.

He may use any sort of technique that rejects the rational side of the patient, so say drugs.

As a psychoanalyst, Jung worries about conversing with people from equal to equal and convincing them logically in what regards thinking and actions.

He may only make use of things that consider the rational side of the clients.

Jung is then more worried about what leads to a certain impulse of the ego or the id or to a certain determination of the superego and Freud is worried about the own impulse.

We ourselves are worried about what could be causing the images in our dreams, for instance.

In this case, the Jungian elements could be of relevance, and if we are right on our observations, of way more relevance.

Notwithstanding, we have already discarded all that could have to do with memories and real-life experiences as a complete explanation for the dreams, so that we are left exclusively with the Collective Subconscious as a hope.

Memories and impulses is what we get as a description for our Collective Subconscious according to our above-mentioned extracts. Memories are out, so that we now have impulses. Impulses end up being our id or our extended id and we have already addressed that when we were talking about the Freudian model, so that the Jungian model is also not complete in what regards our sleep.

\subsubsection{We Are not Ourselves when We Sleep, so Let's Act Coherently}


Since none of the instances of the psyche, according to the models of Freud, Jung, and Pinheiro, could be found in the sleeping body, the person is not themselves at least in those instances.

Thus, there is no point in interrogating a sleeping individual and believing that more truth will come out of them when they are in that state.

We do acknowledge that people who use the sleeping time of others for the purposes of criminal/legal interrogation try to do it when the person is not sleeping (Waxman, $p$. $480,1983)$, so that we do understand that nobody who is in Science really believes that questions asked to a sleeping person will be more truthfully answered than those asked to a person who is awake.

From (Waxman, p. 480, 1983), we read:

A valid explanation of a hypnotic condition or a hypnotic state has been argued for 200 years. Whether it is a waking or a sleeping state, a state of hysteria or any other recognizable psychological condition, has been the subject of much discussion and countless scientific papers. More recently, hypnosis has been described as an altered state of awareness in which distortion of emotion, sensation, image and time can be produced (Waxman 1979); neurophysiological changes have also been described.

It has been shown (Wyke 1957, 1960) that the deeply hypnotized person is not asleep but is in a very special state of relaxation. Electroencephalographic findings indicate that measurable differences exist between waking, sleeping and the hypnotic state (Ulett et al. 1972, Rozhnov 1978).

We then understand that even in criminology what matters is not what we say whilst we are sleeping, but at most what we say whilst we are at most in this special state of relaxation, which we understand is created through special techniques, and is unlikely to be achieved by any other means, say by usual processes of lying down and sleeping. 
In Criminology, there is obviously a concern with the absolute truth, so that nobody should have doubts about this: It is not possible to get to the absolute truth by speaking to a sleeping person.

It is also not possible to get to more truths by speaking to the sleeping person than by speaking to the individual who is awake.

In Kinnoch (2010), we see a man called Daniel describing his interactions with his girlfriend during her sleep.

It is good that it does not look like Kinnoch (2010) believes that what he gets from the girlfriend that way is truer than what he would get otherwise, but what he does is what really matters, since plenty of people seem to do that to others and feel OK with what they do.

LRP used to have sleep talking episodes when she arrived early in the morning (between 1 and 5 AM) at her address in Tijuca, Rio de Janeiro.

In those instances, her mother, LMR, used to approach her through the widely open bedroom door and try to converse with her.

MRP was engaged to RDO in Rocha, Rio de Janeiro, and RDO kept on making suggestions to her during her sleep in order to keep on betraying her and not having her splitting from him or betraying him too.

A group of relatively young people got MRP at her address in St. Kilda East in 2002 and brainwashed her during the night, during her sleep, with several things, one of them being not solving a particular question from a list at her work.

This is the sort of interaction we try to stop.

These should be considered crimes of the worst sort as possible, therefore heinous, since the consequences are always unpredictable, may last for lifetime, and the 
subject would hardly have noticed or would hardly be able to do anything to stop them.

Most of the time, the person is literally sleeping with the enemy, as in Daniel's case.

The point we would like to be making is that this should never be done because it is a horrible crime, and, even though the perpetrator may get the result they think they have aimed at, the result is actually never gotten because the person is not the person when complying with those suggestions, but a modified person, say person', and that is the result of their crime, whilst executing the heinous program.

It would be our sincere desire to also stop the practice of hypnosis, since very few who claim they can do it can actually do it and the consequences of not knowing what they are doing but even so do might be heinous.

To be able to attack this technique (hypnosis) and all alike strategies (Daniel's, LMR's, RDO's, and etc.), we must attack the motivation for the acts.

One of the possible motivations would be getting to the truth more easily. This motivation has already been addressed, we believe.

Another could be playing with the victim: Getting them to do, without ever wanting to, something we really want.

Sometimes we may think that our wishes for the person are the best as possible, so that we may think that we can change their thinking and improve them or improve their life (LMR).

That is the dominant thinking in dictatorship [(Alexander, 1949) and (Parker, 2014)]: That the individual cannot be let to decide on their own what to do with their own life and body.

We could then use the same arguments we use against dictatorship here to make 
our point: That we should never interfere with the sleep of other people unless the people whose sleep we interfere with have given us their consent or the law allows us to do what we are doing.

On the other hand, the universal declaration of human rights, with which we all seem to agree if living in democratic and capitalist countries, says, on its article number 18 (United Nations, 1999):

Everyone has the right to freedom of thought, conscience and religion; this right includes freedom to change their ${ }^{1}$ religion or belief, and freedom, either alone or in community with others and in public or private, to manifest their ${ }^{2}$ religion or belief in teaching, practice, worship and observance.

On its article number 19 (United Nations, 1999), it says:

Everyone has the right to freedom of opinion and expression; this right includes freedom to hold opinions without interference and to seek, receive and impart information and ideas through any media and regardless of frontiers.

We obviously know that if we modify something in the head of a person without their awareness or consent, so say whilst they are sleeping and without them having consented to all we are doing, we are modifying their decisions or thinking somehow and we are therefore violating their right to freedom of thought and to freedom of opinion and expression, and also, possibly, to freedom to hold opinions without interference (articles number 18 and 19 of the Universal Declaration of Human Rights).

Stanley \& Burrows (2001) conclude their studies in hypnosis (pp. 5-6) in the following

\footnotetext{
${ }^{1}$ his in the original.

${ }^{2}$ his in the original
} 
way:

In his reviews MacHovec $(1986,1988)$ reported 86 case examples of adverse effects of hypnosis, with $50 \%$ of cases occurring in a clinical setting, $25 \%$ in research settings and $25 \%$ as a result of stage performances. He generally concluded that the risk of moderate to severe after-effects of hypnosis is 7\% in research and clinical samples and $15 \%$ in relation to stage performances. His review of the complications of hypnosis began by noting under-reporting of adverse effects of hypnosis in the clinical setting. This may occur because most clinicians, when faced with adverse effects, deal with them utilizing their therapeutic skills and hence the complications are short-lived. In his second review of the complications MacHovec (1988) listed 48 adverse symptom reactions reported by participants who had no such previous problems.

If we consider hypnosis as an altered state of consciousness and a form of persuasive communication (Yapko, 1992), then it is not the hypnosis itself that may cause any such harm, but the communication that is associated with the hypnotic process, the context in which the hypnosis takes place and the adequacy of the management of the suggestions given (the appropriateness of suggestions used; individual unwanted associations to the suggestions or state; and failure to adequately complete suggestion removal). As Yapko (1992) noted, it is the unintentionally directed associations to other experiences that may be anti-therapeutic.

The risks of adverse effects may be attributed to subjective characteristics such as psychopathology, previous unresolved emotional trauma, and hypnotizability.

Adverse effects have also been attributed to practitioner characteristics, such as lack of screening for at risk subjects, misdiagnosis of disorders, ambiguous suggestions, inappropriate interventions, ineffective trance termination, and inadequate debriefing.

A review of the clinical and research literature brings us to the following conclusions:

1. There are adverse effects that can arise through the use of 
hypnosis in clinical and other settings.

2. While most adverse effects are transitory and mildly distressing there is the potential for serious deleterious effects, including psychotic decompensation, depressive and panic reactions, and suicidal acting out.

3. There is no evidence that hypnosis per se is the cause of these deleterious effects. Adverse reactions may arise from pre-existing patient vulnerabilities, therapist inexperience in dealing with psychotherapeutic problems, the use of inappropriate suggestions and metaphors, failure to remove unwanted non-therapeutic suggestions, failure to fully reorientate the patient, and failure to debrief the patient adequately.

4. These problems are more likely to arise if the context does not allow them to be adequately addressed (as in stage performances) or if the training and experience of the practitioner is not sufficient for them to deal with the problems as they arise (inadequate training in the areas of hypnosis or psychological functioning).

5. Lay practitioners lacking in the appropriate level of psychological and clinical training are, therefore, more likely to encounter and cause adverse reactions. They are less likely to be able to respond to them therapeutically and ensure the patient's recovery.

6. The practice of hypnosis requires the demonstration of a level of knowledge, skills and supervised training in therapy approaches relevant to the problem being addressed. Most professions require their members to offer treatment only in those fields in which they have appropriate training. The protection of the patient requires this limitation be maintained. 7. Adequate training and accreditation procedures need to be in place to ensure the patient is not subject to treatment approaches of which the practitioner does not have adequate understanding.

8. The use of hypnosis in contexts that pose greatest dangers ought to be controlled or disallowed for the public protection. Despite the claims to the contrary, there are a significant number of reports of serious sequelae following the use of hypnosis on stage.

The figures of adverse effects in hypnosis are then extremely high, and this when we 
consider professionals who work in clinics, practicing the art in a formal setup.

Imagine if we are people who have never studied hypnosis formally?

He generally concluded that the risk of moderate to severe after-effects of hypnosis is $7 \%$ in research and clinical samples and $15 \%$ in relation to stage performances (Stanley \& Burrows, 2001).

We then notice that, when hypnosis is used for the purposes of common men (stage performances, for instance), there is a much higher risk (more than $100 \%$ higher) of the victim suffering from moderate to severe after-effects.

We must observe that very light suggestions, even of non-hypnotic nature, may lead to things as serious as suicide (Schadenberg, 2012).

The reference brings a person giving advice to another and, as a consequence, the other person kills themselves.

The mind is so unknown that we did not even realize that shared ego situations existed until 2014 (Pinheiro, 2014a).

Roberts (p. 2, 2010) tells us that a few possible consequences for the health of the individual of low frequency noise are increased fatigue, reduced memory efficiency, and increased risk of high blood pressure and heart ailments.

The Government of Hong Kong (2014) gives us the following table:

\begin{tabular}{|l|c|}
\hline Source of Sound/Noise & $\begin{array}{c}\text { Approximate Sound } \\
\text { Pressure } \\
\text { in } \mu \mathrm{Pa}\end{array}$ \\
\hline Launching of the Space Shuttle & $2,000,000,000$
\end{tabular}




\begin{tabular}{lc}
\hline Full Symphony Orchestra & $2,000,000$ \\
\hline $\begin{array}{l}\text { Diesel Freight Train at High Speed at } \\
25 \mathrm{~m}\end{array}$ & 200,000 \\
\hline Normal Conversation & 20,000 \\
\hline Soft Whispering at 2 m in Library & 2,000 \\
\hline Unoccupied Broadcast Studio & 200 \\
\hline Softest Sound Human can Hear & 20
\end{tabular}

Table 2: Noise in Hong Kong

We then notice that the difference between speaking to a sleeping person in a whispering tone has ten times less impact on the person's health than speaking to a sleeping person in a tone usually seen in normal conversations, first of all.

Notwithstanding, the pollution involved still reaches, and this provided we stay $2 \mathrm{~m}$ away from the victim and we have the lowest amount of environmental noise as possible (library), the $2000 \mu \mathrm{Pa}$ mark.

Franke (2003) let us know that this is equivalent to $35 \mathrm{~dB}$.

International Labour (1999) tells us that we must add $6 \mathrm{~dB}$ for each time we halve the distance, so that we actually would have $77 \mathrm{~dB}$ at $1 / 64 \mathrm{~m}$ of distance of the head of the person, which is about $1.6 \mathrm{~cm}$.

From reading World Health Organization (2009), we realize that $77 \mathrm{~dB}$ is higher than any value in the tables found on the Executive Summary XIII and XIV, so that a person can get any of the problems appearing on their table if having another person whispering to their heads at a distance of about $1.6 \mathrm{~cm}$.

The most serious ones are probably those mentioned in the Executive Summary XIV: psychic disorders (60 dB), myocardial infarction (50 dB), and hypertension (50 dB). 
It can only be that whispering to the head of a person as they sleep without their consent is a civil crime then.

\section{Soul/Spirit and Sleep}

We could easily call the collective unconscious soul, since at least part of the soul from Spiritism can be described in the way Jung described the collective unconscious.

See:

Certainly, later in life Jung downplayed the "biological" aspect of his psychology, and even discarded it altogether, preferring to see the archetypes in a more Platonic sense of prexistent spiritual entities. And in his voluminous alchemical writings he was more concerned with the dynamics of the psyche, and its transformation, than with explaining how the psyche or the archetypes came about in the first place. So it would be unfair to judge Jung on these grounds. Jung himself obviously did not consider abstract theories concerning the metaphysical or cosmological origin of the archetypes as important a practical here-and-now understanding of how the psyche worked, and how spiritual transformation and the growth to greater wholeness occur.

(Kazley, 2014)

See also (Gad, 2000):

Being that has soul is living being. Soul is the living thing in [us], which lives of itself and causes life

Still in (Gad, 2000):

If they have absolutely no hope and no door open to the transcendent and 
they remain only at the concrete level of reality, they will miss out on that which, for Jung, was a natural alternative level of reality, which is the spiritual aspect of our soul.

\section{The spiritist's theory}

When we sleep, our spirit travels and meets with other spirits; some of our dreams take us to places our spirits actually visit." "Spirits progress through many levels, moving from the denser locations close to earth to higher planes where they associate with others like themselves and eventually do not need to return to material incarnations.

(Welsh, 2011)

Seen from the spiritualists' perspective, there is no body, but there is still soul as one sleeps.

See also:

Every night, while most of us sleep, our spirits separate from the earthly confines and visit the Spirit world. We often experience that visitation through dreams.

Stefanidakis (2001)

and

400. L'Esprit incarné demeure-t-il volontiers sous son enveloppe corporelle?

"C'est comme si tu demandais si le prisonnier se plaît sous les verrous. L'Esprit incarné aspire sans cesse à la délivrance, et plus l'enveloppe est grossière, plus il désire en être débarrassé. " 
401. Pendant le sommeil, l'âme se repose-t-elle comme le corps?

"Non, l'Esprit n'est jamais inactif. Pendant le sommeil, les liens qui l'unissent au corps sont relâchés, et le corps n'ayant pas besoin de lui, il parcourt l'espace, et entre en relation plus directe avec les autres Esprits.

402. Comment pouvons-nous juger de la liberté de l'Esprit pendant le sommeil ?

"Par les rêves. Crois bien que lorsque le corps repose, l'Esprit a plus de facultés que dans la veille; il a le souvenir du passé et quelque fois prevision de l'avenir; il acquiert plus de puissance et peut entrer en communication avec les autres Esprits, soit dans ce monde, soit dans un autre. Souvent, tu dis: J'ai fait un rêve bizarre, un rêve affreux, mais qui n'a aucune vraisemblance; tu te trompes; c'est souvent un souvenir des lieux et des choses que tu as vus ou que tu verras dans une autre existence ou à un autre moment. Le corps étant engourdi, I'Esprit tâche de briser sa chaîne en cherchant dans le passé ou dans l'avenir. ”

(Kardec, 1857)

In the spiritists' model of psyche therefore we would have at least the id, the ego, the superego (which would include our soul) when we are awake and the soul and the body when we are asleep.

\section{Dreams}

We should examine other theories about dreams to make sure that we are not being partial when choosing the spiritist's theory as the best theory to explain the phenomenon dream.

In Aoyama (2012), we read:

At first he believed in Hobson's theory, but as he carried out studies of 
people with brain injuries, he realized that some continued to have dreams despite sustaining damage to their brain stem, which Hobson posited as the switch that activated dreams. In contrast, he discovered that people cease to have dreams when the frontal part of the brain controlling urges is damaged.

In Horvath (2015), we read instead:

The prefrontal cortex also projects to other brain regions associated with addictive problems. These include the reward system; memory and emotion; and stress regulation centers of the brain. Therefore, damage to the prefrontal cortex may further interfere with the functioning of these other brain regions as well.

We then learn that the piece of the brain that most has to do with dreams is the frontal part, which we have deemed to be the one to control our urges, but, as we can see in the last extract here mentioned, we also have deemed it to be related to emotions, stress, and etc.

Still in Aoyama (2012), we read:

Solms theorized that dreams originate with the urge to do something, which is expressed using information stored in the brain. In other words, dreams are manifestations of urges, meaning that Freud's theory was not incorrect.

Urge to do something may as well be urge to be together with the spirits, right?

However, there are other points that could be made here. Notice, for instance, that we cannot guarantee that that part of the brain that controls urges controls or stores only that, and this is what we have already said here: That it actually controls more than that. It also controls emotions, stress, and etc. 
When Aoyama (2012) says that Freud's theory was not incorrect, he means that

In Freud's "The Interpretation of Dreams," published in 1900, he asserted that dreams are the manifestations of urges and desires that we keep suppressed in the realm of our subconscious

Once more, this urge or desire that we keep suppressed in the realm of our subconscious could as well be the urge or desire of sharing things with the spiritual world.

We still read in Aoyama (2012) that

Hobson's theory views dreams as an activity close to a sensory perception in response to some form of stimulation. On the other hand, Solms' definition of dreams as manifestations of urges sees them as an activity akin to closing your eyes and picturing something, which is to say that they are closely related to our imagination.

Notice that something that be close to a sensory perception in response to some form of stimulation may as well be a sensory perception in response to a transmission of some sort from the spiritual world. Remember here that we believe we have proven that we do not use our imagination whilst we sleep.

Still in Aoyama (2012), we read:

In a recent thesis, Hobson claims that in the middle of REM sleep, "the brain is prepared to activate consciousness right after we awake," and describes this state as "protoconsciousness." Dreams are virtual experiences created from visual information stored in the brain that is connected together during protoconsciousness. "When I read it, I thought, 'This is 90 percent the same as my own theory,' " says Solms.

Dreams are created from visual information stored in the brain could easily imply that 
this information entered the brain through a Wi-Fi sort of process, could it not? In this case, it could still come from the spiritual world.

Here we must remember that we believe that we have proven that we cannot be remembering or organizing things as we sleep, that things are more like watching TV during that time.

One of our counter-arguments to the hypothesis that we could be closing our eyes and imagining things as we sleep was the existence of the premonitory dreams.

An enormous number of human beings have reported to have had at least one premonitory dream in their lives.

We could not imagine things so well that they happen precisely as we imagined in a future time, one would think.

On the other hand, our desire that something happen also does not seem to be enough to cause that thing to happen ever, especially precisely as we have desired that it did.

In this case, we would have to be passive in this process somehow.

Premonitory dreams are mentioned, for instance, in (Wiseman, 2011). The most interesting piece of information in (Wiseman, 2011), and that is a text that has been written by a professor from Hertfordshire (Wiseman, 2010), is that the psychiatrist John Barker, by 1966, would have collected about 60 reports on premonitory dreams regarding a major disaster (Aberfan's) and only about 36 of these cases involved dreamers who did not produce evidence on having dreamed about the events before they happened.

What is happening here, with some parts of the research results we have mentioned, is that the way they measure the brain activity to determine if we are dreaming or not is electricity: They make use of the EEGs. If we do not have stress or emotions in 
general, it is likely that we do not have those changes in electricity patterns that make the EEGs go up and down, and it is through those detected changes that we get to know, still nowadays, if a person is dreaming or not.

The conclusion is obvious: A person without that part of the brain may still dream, but is not able to feel emotions and stress, and therefore the EEGs detect no activity.

Chudler (2015) lets us know that we have EEGs, EMGs, and EOGs to let us know about the human activity during sleep time. EMGs would detect muscular movements and EOGs would detect eye movements.

We could not find any study that used anything beyond EEGs to detect activity during sleep in humans without the frontal part, however.

\section{The Urges}

Since Solms' best theory is that (Aoyama, 2012) we dream because of our urges, perhaps we should deepen our thinking on this item.

Sharma \& Sharma (2006) let us know that some psychologists have cited frustration as an important cause of war.

Sharma \& Sharma (2006) also state that the most dangerous forms of aggressive behaviour are the consequences of sex frustration.

Rummel (2013) states that we all have experienced irritation and anger at some frustrations and also that not all frustrations lead to anger.

Rummel (2013) also tells us that Gurr (1969) stated that the anger induced by frustration, however, is a motivating force that disposes men to aggression, irrespective of its instrumentalities.

If dreaming is a result of us having urges, then it should be understood that we are 
dealing with those urges somehow as we dream, perhaps satisfying them to best that we can, like dealing with them in a much more intelligent way than we would be doing that if using our defense mechanisms (McLeod, 2006).

McLeod (2006) states that Ego-defense mechanisms are natural and normal. When they get out of proportion, neuroses develop, such as anxiety states, phobias, obsessions, or hysteria.

This means that if we apply defense mechanisms, we can get really serious problems.

Dreams, according to both Solms and Freud (Aoyama, 2012), would relieve us from our urges without going through the defense mechanisms.

The possibility that some people do not dream but rest even so is not as important as the possibility that our dreams relieve us from urges that could otherwise make us exhibit pathological or harmful behavior whilst interacting with other human beings.

In any hypothesis, only a very insignificant minority of us has been told to not dream (Domhoff, 2001).

Domhoff (2001) says that there is a minority of people who are able to sleep even though they do not dream.

Here, again, we put in doubt these results based on the fact that they probably used exclusively the EEGs to decide on whether the person was dreaming or not.

Even if they had used the EMGs, the fact that there is no muscular movement may simply mean that they do not have the feelings that would normally lead to muscular movement of some sort during sleep, so say they do not have the frontal part of the brain or it is not functional or it is not entirely functional.

And even if they had used the EOGs, there might be another explanation for them not to exhibit REM during sleep, if that is what has happened, an explanation that is 
not not dreaming.

Since we have agreed, as a race, that we should always consider the majority in our decisions, not the minority, and dreaming is likely to be a tool to keep us sleeping, therefore resting, or a tool to communicate with the spiritual world, which we miss and need to communicate with, also for enlightenment, or a tool to relieve us from urges, we should obviously not let people interfere with our natural sleep processes.

If someone interrupts our processes of communication with the spiritual world, then the message that we so much need, such as the information about the eminent catastrophe, may not be passed to us. If one interrupts our process of recovery of energy, we may not have enough to perform to our standards or wishes on the next day. If one interrupts our processes of relief from urges, then we may end up having as only alternative the defense mechanisms, which may lead to permanent or temporary unacceptable social behavior, which may actually injure society tremendously, to the point of causing wars.

We also have all those health hazards appearing when our normal sleep processes are disturbed, and this even if they are disturbed by what could be called light human interference (whispers to the head).

Notice that our dreams could not be simply relief of urges if we have premonitory ones.

They could also not be simply fruits of our imagination for the same reason. They also cannot be the fruits of our imagination because of the figures from the studies on energy expenditure.

\section{The Best Possible Explanation and Science}

The scientific method does involve selecting the best possible explanation for each phenomenon we study. 
Doyle (2014) tells us that

Inference to the Best Explanation is a kind of abductive reasoning identified by Gilbert Harman in 1965. He called it abductive reasoning, but Harman's definition of abduction did not correspond exactly to Charles Sanders Peirce's triple of Deduction, Induction, and Abduction.

Peirce had himself noted that all thinkers infer explanations - that is, hypotheses that might explain - various phenomena.

One of the classic examples is how to explain wet grass. If the grass is wet, it probably rained. Rain is the best explanation for wet grass, especially in Peirce's New England. But it need not be the best explanation in Arizona at the height of the dry season, where automatic sprinkler systems might be the best explanation for wet grass - especially if the grass is wet but the street is dry.

Peircean abduction is the free creation of hypotheses that generate predictions which can be tested by further observations. For example, the sprinkler hypothesis suggests looking at the street. Observing the street to be dry provides experimental confirmation of the sprinkler hypothesis relative to the rain hypothesis.

Gilbert Harman says:

"The inference to the best explanation" corresponds approximately to what others have called "abduction," the method of hypothesis," "hypothetic inference," "the method of elimination," "eliminative induction," and "theoretical inference."

I prefer my own terminology because I believe that it avoids most of the misleading suggestions of the alternative terminologies.

In making this inference one infers, from the fact that a certain hypothesis would explain the evidence, to the truth of that hypothesis. In general, there will be several hypotheses which might explain the evidence, so one 
must be able to reject all such alternative hypotheses before one is warranted in making the inference. Thus one infers, from the premise that a given hypothesis would provide a "better" explanation for the evidence than would any other hypothesis, to the conclusion that the given hypothesis is true.

With this, we can safely utter that our dreams are consequences of interactions with the spiritual world, since we do not have any other hypothesis.

We have analyzed the possible explanations of a few researchers (Solms, Freud, Hobson, and Aoyama, for instance) and the models of the human psyche of Freud, Jung, and Pinheiro.

We found opposition that we believe to be sound to each one of the other explanations and models.

\section{On Love and Modifying the Person We Claim to Love against Their Will}

We want to approach this from a logician's point of view.

Assume we claim to love a person $X$. Person $X$ is formed of their entire psyche at least.

As we claim in Words for Science (Pinheiro, 2014b), the words we use in Science have to be extremely well selected/defined.

Love is not well defined in our dictionaries, for we have, for instance, that love is love $X$

$n$.

1. A deep, tender, ineffable feeling of affection and solicitude toward a per son,

such as that arising from

kinship, recognition of attractive qualities, or a sense of 
underlying oneness.

2. A feeling of intense desire and attraction toward a person with whom on $e$ is disposed to make a pair; the emotion of sex and romance.

3.

a. Sexual passion.

b. Sexual intercourse.

c. A love affair.

4. An intense emotional attachment, as for a pet or treasured object.

5. A person who is the object of deep or intense affection or attraction; bel oved.

Often used as a term of endearment.

6. An expression of one's affection: Send him my love.

7.

a. A strong predilection or enthusiasm: a love of language.

b. The object of such an enthusiasm: The outdoors is her greatest love.

(love, 2013)

As discussed in Words for Science (Pinheiro, 2014b), feeling, for instance, is not a suitable word for Science. Passion ALSO is not.

We can actually define love as a capacity of neglecting our wishes, intents or interests in the name of keeping the same level of attachment to another entity or in the name of increasing it for our purposes here.

The greater the love, the greater the capacity.

If we say we love $X$, we then mean that we are able to neglect our wishes, intents or interests in the name of keeping the same level of attachment to $X$ or in the name of increasing it.

So, first of all, loving implies sacrifices: There is no love without sacrifices. 
Where does the need to change a person against their will originate?

Some things are reasonable: Say we have allergy to cigars and the person has just started with this habit, so that they did not have it when we met them, and we want them to quit smoking.

Some things are unreasonable: Say we like dressing red and think that red matches pink, so that we would like the person to wear pink when we wear red, but they refuse to do that.

Notwithstanding, the discussion is not about whether the change we would like to see in the person is reasonable or not. The discussion is about whether we are allowed to think of making that change happen without their consent.

We have already explained, with foundations in human history and human choices (human rights declaration), why we would have the majority of human kind opposing this possible choice of action.

We now would like to make a logical point.

Humans are mutants: They seem to enjoy changing themselves into someone else once in a while.

Some changes are permanent, others are not.

If we like $X$, that does not mean that we like $X^{\prime}$, the version of $X$ who smokes, for instance.

We are allowed to change our heart or decisions as $X$ changes, so that we can split from $X$ alleging we loved $X$, but we do not really love $X$ ', for instance.

The population of the world seems to be well distributed in terms of gender, as we can see from reading (United Nations, 2012), so that a person who splits from 
another should always be able to find a partner from the opposite gender.

If the other person would not quit smoking to be with us and we have allergy, then it seems to us that they actually do not love us, since the essence of love should be sacrificing our wishes in the name of the relationship.

If we want this person as an object, and therefore their feelings do not matter to us, just the fact that we think we have them, we must understand that we actually do not love them, since they are obviously a human being, not an object.

We can call their version, which exists only in our head, $X "$.

In any hypothesis, that just means that we actually do not love $X$.

We must be aware of the fact that wishing for keeping on relating to a person who is not being considered as a person by us has to be a disease of some sort, so that this is definitely not a healthy choice.

No doubts there are a number of cases in human history in which one human being has, for instance, killed the other to then sleep with them.

One of those is (BBC, 2014).

We would obviously know that this is mental illness: The person is not important, meaning the victim is not a person for those who do that; important is just the feeling of accomplishment they get for doing what they are doing (I am now sleeping with her or something).

It is trivially the case that if you can disable a person, say by attacking criminally and physically their head, then you should be able to do whatever you want with them, including sex and sleeping together with them.

Rhodan (2014) lets us know of a married man who would have had sex with at least 
100 corpses during his shifts at the morgue.

We should know that a person who cannot relate normally to a similar being has to have some mental problem.

In the case with (Rhodan, 2014), the perpetrator confesses depending on alcohol and drugs and being high on them by the time of most of the offences.

Dependency on drugs and alcohol is equated to mental illness for long: It is a common thing seeing alcoholics and drug addicts attending psychiatric wards and undergoing therapy whilst making use of psychiatric medication (The Trustees, 2014).

Purse (2014) brings information about sociopathy, which could be one of the causes for a person to wish for changing the other whilst they apparently relate to them.

Basically, suppose we succeed in changing the behavior of $X$ by making sleep time suggestions to them, say we put in their head that they must love us unconditionally, regardless of what we do.

We need to be aware that what we have done is criminal, since they have never consented.

Besides, it has to be the case that we are suffering from a temporary or permanent mental illness because we cannot accept $X$ as they are and yet we insist in being with them.

We must also understand that our $X$ is not our $X$ anymore after we have done what we have done to them: Our $X$ is now $X$ ' or $X$ '.

We therefore cannot claim to love $X$. We love $X^{\prime}$ or $X^{\prime \prime}$, which is, basically, our Frankenstein. 
Given the possible irreversibility of our actions, and the injuries that $X$ gets because of them, we are now legally liable and may be the target of a suit, as a minimum thing.

\section{Implications of the Findings}

What follows is that there is nothing that should be more protected by the law than the sleeping person, nothing that should deserve any more care in human kind, in terms of protective equipment and environment.

If we are spiritists, we may say that all this probably implies that any human interference with the sleep of a person may stop spiritual progress, may prevent us from knowing of bad events that are yet to occur, and therefore prevent us from being warned and well prepared for them, and may still modify life in this world because it all may depend on the spiritual interactions during our sleep.

The previous paragraph could be escaping the intentions of this paper, which should have to do exclusively with Science. However, we believe we have proven that only the spirit, as imagined by humans, will fill the gaps regarding what could be making the sleeping person still be somehow in activity. In this case, the theory is suitable and forms a valid thesis for other scientific investigations.

The scientific method involves choosing the best explanation as possible for an event and then explore all possibilities after that to prove or disprove that best explanation available and then perhaps come up with a better one (Doyle, 2014).

Our psyche involves therefore at least four levels of energies: id, ego, superego, and supernatural.

With us on this one would be people like Jung (Kazlev, 2013), since this has a lot to do with the theory of the collective unconscious (AlleyDog.com, 1998-2003).

Some people hold this funny belief that they will get to know the real us if they speak 
to us as we sleep or if they can read our instinctive thoughts, that is, our incomplete egoic decision formation.

It is all nonsense because that is when we are definitely someone else or something else, as explained earlier on in this paper.

The individual is obviously a result of at least the sum of the id with the ego.

If we find out what their id thinks, that is, the thought preceding action, then that means nothing, for that thought may become action, but may not become too.

Basically, the individual is the conscious decision over the id at least.

Some people find it wonderful that subliminal messages may change the individual into what they want.

If one is spiritist, however, they think that each and every time that happens, a catastrophe of no precedent in the spiritual world also happens and that generates disgraces from the similar beings, once if you pay attention, for a spiritualist, it can only be the case that the somnambulist who died at night, jumping from the window, was told to do so by the spiritual world, and that is just one form of spiritual consequence in our world of the similar beings.

On the other hand, if the person is not a spiritist person, then they do not know what they are dealing with, for if the sleeping body is not described by any of the theories that we have studied here (Freudian, Jungian or Pinheiro's), and we have proven that it cannot be, it is nothing that we can explain, therefore the consequences of playing with those who are asleep are unpredictable, and therefore should be feared by all of us until we at least know what we are dealing with.

There are still several more widely accepted reasons not to interfere with the human sleep/dream: It relieves us from our urges and those may even lead to wars if not relieved. They may also bring serious illnesses. 
People speaking to us in a whispering tone may cause serious illnesses to us as well, illnesses that go from stress to psychosis.

\section{Conclusion}

During our sleep, none of the psyche elements mentioned by Jung, Freud or Pinheiro should be active, so that we do not really know what is active whilst we sleep.

After considering a few well-known hypotheses, it seems that the best explanation is that our mind works like a dumb computer terminal during sleep time and we therefore receive images from somewhere else when we dream.

Despite the theories of Garfield and her fellow researchers, it seems that having a lucid dream is something very rare and even though one may be able to have those if using their techniques, the process seems to be very hard to go through.

It is all definitely unnatural, to the least.

We seem to be able to do very little to change the contents of our dreams.

From looking at empirical medical data regarding patients with damaged frontal brain piece, it seems true that we have dreams because we want to have them, since the area that relates directly to those also relates to our urges (Freudian language).

Upon closer scrutiny, however, this theory is proved not to be that sound, for there are way more elements to our frontal brain piece, such as stress and emotions, and the way we tell if a person is dreaming or not in Science has usually been the EEGs.

After we discard all elements of the psyche mentioned by Jung, Freud, and Pinheiro, we are left with a few researchers' suggestions, including imagination.

We have considered those suggestions and found opposition that seems to be sound to each one of them. 
When imagination was considered, we used the energy expenditure during sleep time to prove that that is not possible.

Our dreams should also not be the fruits of any sort of activity that be superior, in terms of brain usage, to the activity of watching TV, so that we should not be organizing images or ideas as we sleep.

In this case, we are left with spiritism and the theory of interaction between our spirit and the spirit of others during sleep.

To this theory, we found no opposition, so that we chose it as the best possible explanation to our dreams.

As everything else in Science, in case the consequences are analyzed and reveal inconsistencies or in case a better explanation, to which even less opposition is found, appears, we will then have to drop ours, but, so far, this is the best possible explanation and therefore the preferred explanation for Science.

A good diagram to illustrate the scientific method is found at (McClean, 2000). We put that together with (Doyle, 2014) to get a model for the modern scientific method, which is what we are using to claim that our choice is strictly scientific.

The spiritists would probably like to propose a new model for the human psyche. Considering what we have quoted here, this model would have to contain at least id, ego, superego, body, and soul.

All practices that involve interfering with the sleep of a person should be condemned: From disease to death, from spiritual to physical, and even from personal to world consequences, all is there to tell us not to do it.

Wishing for changing a partner somehow against their will just means that we do not actually love them and acting upon that may lead to us having to face serious legal consequences for our acts. 
Even hypnosis should be a condemned practice, given the so much chance that we have of producing moderate to severe after-effects on the victim.

Interfering with the sleep of a human being without their consent might compare to the most condemned practices in dictatorship and therefore might be the same as violating human rights.

There cannot be any more truth to the discourse of a sleeping subject than there is to their discourse when awake because the sleeping subject is not exactly themselves. Wishing for interfering with our partner's sleep without their consent is probably a sign that we are mentally unwell. 


\section{REFERENCES}

Pinheiro, M. R. (2014a). A New Model for the Human Psyche. Journal of Research in Humanities and Social Sciences. Vol. 2, issue 5, pp. 61-65. ISSN (Online): 23219467

Thornton, S. P. (2014). Sigmund Freud (1856-1939). Retrieved June 202015 from http://www.iep.utm.edu/freud/

Rosen, D. (2012). How Much Do Sleep-Talkers Reveal During Sleep. Retrieved December 12013 from http://www.psychologytoday.com/blog/sleepingangels/201204/how-much-do-sleep-talkers-reveal-dur ing-sleep

Rabogie. (2010). "Sleep Talking" Does the truth come out? Retrieved December 1 2013 from http://answers.yahoo.com/question/index?qid=20110210101352AAbcTBz

Suelen. (2011). Quando a pessoa fala dormindo, o que ela diz e verdade? Retrieved December 1 2013 from http://br.answers.yahoo.com/question/index?qid=20111011182445AA9ynuv

Coco, P. (2013). Adoro pessoas que falam a dormir. Retrieved December 12013 from http://pippacoco.blogspot.com.au/2013/03/adoro-pessoas-que-falamdormir.html

Cliff's List. (2013).Hypnotic Commands During Sex. Retrieved December 12013 from http://cliffslist.com/index.php/hypnotic-commands-sex/

Encyclopaedia Britannica. (2015). Arquimede's Principle. Retrieved June 102015 from http://www.britannica.com/EBchecked/topic/32827/Archimedes-principle

Doyle, B. (2014). Inference to the Best Explanation. Retrieved October 192014 from http://www.informationphilosopher.com/knowledge/best explanation.html 
AAPH. (2011). Hypnosis FAQ: Frequently Asked Questions - What is Hypnosis? Retrieved December 22013 from http://aaph.org/hypnosis-FAQ\#What2

World Health Organization. (2009). Night Noise Guidelines for Europe. Retrieved $\begin{array}{llll}\text { October } & 12 & 2014 & \text { from }\end{array}$ www.euro.who.int/ data/assets/pdf file/0017/43316/E92845.pdf

Franke, S. (2003). Space Hardware Acoustic Mitigation. Retrieved June 102015 www.colorado.edu/ASEN/.../Space-Hardware-Acoustic-Mitigation.pdf

International Labour Organization. Your health and safety at work. (1999) Retrieved $\begin{array}{lllll}\text { October } & 12 & 2014 & \text { from } \quad \text { http://actrav.itcilo.org/actrav- }\end{array}$ english/telearn/osh/noise/nomain.htm

Minha noticia. (2007). Jovem alemao pula de $4^{\circ}$ andar enquanto dorme. Retrieved December 2013 from http://minhanoticia.ig.com.br/editoria/Inusitadas/2007/09/04/jovem alemao pula de 4 andar enquanto dorme 2076809.htm

Pinheiro, M. R. (2013). Note on Zeno's Dichotomy. Protosociology, vol. 30.

Schutz, R. (2014). Stephen Krashen's Theory of Second Language Acquisition. Retrieved September 302014 from http://www.sk.com.br/sk-krash.html

Roberts, E. (1998). Freud's Theory of Personality. Retrieved September 292014 from http://www.d.umn.edu/ revans/freudtheory.htm

Sichel, M. (2009). Humble Men and Confident Women Are More Successful. Retrieved June 172015 from https://www.psychologytoday.com/blog/the-therapist-isin/200910/humble-men-and-confident-women-are-more-successful

McLeod, S. (2009). Jean Piaget. Retrieved December 102013 from http://www.simplypsychology.org/piaget.html

American Community Corrections Institute. (2003). Cognitive Development. 
Retrieved December 12013 from

development/

CGN. (2011). Homem sonambulo pula de predio de hotel. Retrieved December 2 2013 from http://cgn.uol.com.br/noticia/10956/col-icon-more

Netcina. (2013). Video: Estudante sonambulo pula do $5^{\circ}$ andar do predio. Retrieved December 22013 from http://www.netcina.com.br/2013/06/estudante-sonambulopula-do-5-andar-do.html

Lopes, A. L. (2011). O que sao mensagens subliminares? Retrieved December 2 2013 from http://mundoestranho.abril.com.br/materia/o-que-sao-mensagenssubliminares

Garfield, P. (1977). Sonhos criativos. Rio de Janeiro: Nova Fronteira.

Valli, K., \& Revonsuo, A. (2009). The Threat Simulation Theory in the Light of Recent Empirical Evidence - Review. American Journal of Psychology, 122, pp. 17-38.

National Park Service. (2014). Denning and Hibernation Behavior. Retrieved October 22014 from http://www.nps.gov/yell/naturescience/denning.htm

Starner, T. (1996). Human-powered wearable computing. IBM Systems Journal, vol. 35, no. 3-4.

Harvard University. (2000). Calories burned in 30 minutes for people of three different weights. Retrieved October 62014 from

http://www.health.harvard.edu/newsweek/Calories-burned-in-30-minutes-of-leisureand-routine-activities.htm

Proserve Technology, Inc. (2013). Study finds Scary Movies end up Burning Calories depending on. Retrieved October 212014 from http://www.briefingwire.com/pr/studyfinds-scary-movies-end-up-burning-calories-depending-on 
Thiedke, C. C. (2001). Sleep Disorders and Sleep Problems in Childhood. Retrieved October 62014 from http://www. aafp.org/afp/2001/0115/p277.html\#sec-4

Freud, S. (1900). The Interpretation of Dreams. Retrieved October 62014 from http://www.free-ebooks.net/ebook/The-Interpretation-of-Dreams

Welsh, T. (2011). Spiritists Seek the Unseen World and its Wisdom. Retrieved December 22013 from http://www.theseekerbooks.com/articles/spiritists.htm

Kazlev, M. A. (2013). Jung's Conception Of The Collective Unconscious. Retrieved December $\quad 9 \quad 2013$ from http://www.kheper.net/topics/Jung/collective unconscious.html

Engler, B. (1999). Personality Theories: An Introduction. Retrieved October 72014 from

http://books.google.com.au/books?id=Ue4WAAAAQBAJ\&pg=PA70\&lpg=PA70\&dq=a nima+jung+opposite+sex+qualities\&source=bl\&ots=geCDFAzV1R\&sig=bbWyS-dv1Es7O5G3jGRwFZfng4\&hl=en\&sa=X\&ei=rTEzVKD7DsS4ygOb3YHgCQ\&ved=0CDIQ $\underline{6 A E w A w \# v=0 \text { epage } \& q=a n i m a \% 20 j u n g \% 20 \text { opposite } \% 20 \text { sex\%20qualities\& } f=f a l s e}$

C. G. Jung Society of Atlanta. (1999). The Shadow. Retrieved October 72014 from www.jungatlanta.com/articles/spring99-shadow.pdf

Stein, M. (2013). Jung's Map of the Soul: An Introduction. Chapter 5. Retrieved October 172014 from

http://books.google.com.au/books?id=fGAQO8Qmij8C\&pg=PT91\&lpg=PT91\&dq=the +shadow+is+in+the+ego+jung\&source $=$ bl\&ots $=x y 2 i T O 6 Y$ sj\&sig $=2 \mathrm{~L} \quad \mathrm{Ngndh} I T H j \mathrm{PvHC}$ $\underline{A V w} \mathrm{~S}-$

hO9MA\&hl=en\&sa=X\&ei=IIZAVJ pKeevygPH4YGYDA\&ved=0CDEQ6AEwBDgU\#v= onepage\& $q=$ the $\% 20$ shadow\%20is\%20in\%20the\%20ego\%20jung\&f=false

Miller, M. C. (2010). Unconscious or Subconscious? Retrieved October 72014 from http://www.health.harvard.edu/blog/unconscious-or-subconscious-20100801255 
Reich, L. (2003). Lucid Flight. Retrieved October 72014 from http://www.worlddreambank.org/L/LUCIFLY.HTML

Hopwood, A. (2006). Jung's Model of the Psyche. Retrieved October 72014 from http://www.thesap.org.uk/jung-s-model-of-the-psyche

C.G. Jung Institute of Chicago. (2010). Analytical Psychology. Retrieved October 17 2014 from http://www.jungchicago.org/pages.php?page=ap

Kellogg III, E. W. (2005). Handout \#1 Lucid Dreaming Group. Retrieved October 17 2014 from sonoma.edu/users/v/vannuysd/322/Lucid+Dreaming+Handout.pdf

Jungian Center for the Spiritual Sciences. (2013). Components of Individuation 1: What is individuation? Retrieved October 17 2014 from http://jungiancenter.org/essay/components-individuation-1-what-individuation

Encyclopaedia Britannica. Inc. (2014). Collective Unconscious. Retrieved October 7 2014 from http://www.britannica.com/EBchecked/topic/125572/collectiveunconscious

Wayan, C. (1969). First Dream Flight. Retrieved October 72014 from http://www.worlddreambank.org/F/FIRSFLIT.HTM

Waxman, D. (1983). Use of hypnosis in criminology: discussion paper. Journal of the Royal Society of Medicine, vol. 76(6), pp. 480-484. Retrieved October 82014 from http://www.ncbi.nlm.nih.gov/pmc/articles/PMC1439196/?page=1

Kinnoch, D. (2010). My Girlfriend's Complete Honesty While Sleeping Talking. Retrieved October 82014 from http://www.end-your-sleep-deprivation.com/mygirlfriends-complete-honesty-while-sleep-talking.html

Alexander, L. (1949). The Molding of Personality under Dictatorship: The Importance of the Destructive Drives in the Socio-Psychological Structure of Nazism. Journal of 
Criminal Law and Criminology, vol. 40, issue 1, article 2.

Parker, N. G. (2014). History of Europe. Retrieved October 92014 from

http://www.britannica.com/EBchecked/topic/195896/history-of-Europe/58477/Thetrappings-of-dictatorship

United Nations. (1999). The Universal Declaration of Human Rights. Retrieved October 92014 from http://www.un.org/en/documents/udhr/

Stanley, R. O., \& Burrows, G. D. (2001). International Handbook of Clinical Hypnosis. John Wiley \& Sons Ltd.

Schadenberg, A. (2012). British Columbia man charged with counseling depressed woman to commit suicide. Retrieved October 92014 from

https://www.lifesitenews.com/blogs/british-columbia-man-charged-with-counsellingdepressed-woman-to-commit-sui

Roberts, C. (2010). Low Frequency Noise from Transportation Sources. Proceedings of $20^{\text {th }}$ International Congress on Acoustics (ICA), vol. 1.

The Government of Hong Kong. (2014). Characteristics of Sound and the Decibel

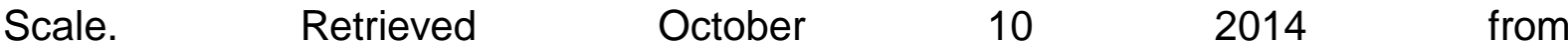
http://www.epd.gov.hk/epd/noise education/web/ENG EPD HTML/m1/intro 5.html Kazley, M. A. (2004). Jung's Conception of the Collective Unconscious. Retrieved June 212015 from http://www.kheper.net/topics/Jung/collective unconscious.html

Gad, I. (2000). Jung's Model of the Psyche. Retrieved December 152013 from http://www.jung.org/jungs\%20model\%20of\%20the\%20psyche gad.html

Stefanidakis, S. (2001). Life in the Spirit World: Part One. General Introductio. Retrieved December 9 from http://www.fst.org/sptwld1.htm

Kardec, A. (1857). Le Livre Des Esprits. Retrieved December 92013 from 
http://www.allan-kardec.com/

Aoyama, N. (2012). What are dreams? Psychology, neuroscience try to explain them. $\begin{array}{lllll}\text { Retrieved } & \text { December } & 17 & 2013 & \text { from }\end{array}$ http://ajw.asahi.com/article/globe/feature/dream/aj201208260022

Horvath, A. T., Misra, K., Epner, A. K., and Cooper, G. M. (2015). Impaired Decisionmaking, Impulsivity, and Compulsivity: Addictions' Effect on the Cerebral Cortex.

$\begin{array}{llll}\text { Retrieved } \quad \text { June } & 17 & 2015 & \text { from }\end{array}$ http://www.sevencounties.org/poc/view doc.php?type=doc\&id=48374\&cn=1408

Wiseman, R. (2011). Can Dreams Predict the Future? Retrieved December 172013 from http://www.sott.net/article/224772-Can-Dreams-Predict-the-Future

Wiseman, R. (2010). Biography. Retrieved December 172013 from http://www.richardwiseman.com/biography/biog.html

Chudler, E. H. (2015). What is Sleep... . Retrieved June 172015 from http://faculty.washington.edu/chudler/sleep.html

Sharma, R. N., \& Sharma, R. (2006). Experimental Psychology. Retrieved December 182013 from

http://books.google.com.au/books?id=f8fJu3jSXJ0C\&pg=PA222\&lpg=PA222\&dq=fru stration+sublimatio

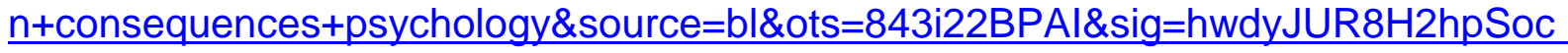
LB0jayff $7 Z 58 \& h|=e n \& s a=X \& e i=| t-$

wUo2MKYW3iQeCu4DQCg\&ved=0CGkQ6AEwBw\#v=onepage\&q=frustration\%20su blimatio $n \% 20$ consequences\%20psychology\&f=false

Rummel, R. J. (2013). Understanding Conflict and War: Vol. 3: Conflict in Perspective Chapter 3 Frustration, Deprivation, Aggression, And The Conflict Helix. Retrieved December 182013 from http://www.hawaii.edu/powerkills/CIP.CHAP3.HTM 
Gurr, T. R. (1969). A Comparative Study of Civil Strife, in Hugh Davis Graham and Ted Robert Gurr (Eds.), Violence in America. New York: Bantam Books, pp. 572-632.

McLeod, S. (2008). Defense Mechanisms. Retrieved December 182013 from http://www.simplypsychology.org/defense-mechanisms.html

Domhoff, G. W. (2001). Why did empirical dream researchers reject Freud? A critique of historical claims by Mark Solms. Retrieved December 182013 from http://www2.ucsc.edu/dreams/Library/domhoff 2004c.htm

Pinheiro, M. R. (2014b). Words for Science. Indian Journal of Applied Research. Retrieved June 10 2015 from

http://www.theglobaljournals.com/ijar/articles.php?val=NjQ0MQ==\&b1=853\&k=214

love. (n.d.) The American Heritage ${ }^{\circledR}$ Dictionary of the English Language, Fourth Edition. (2003). Retrieved October $19 \quad 2014$ from http://www.thefreedictionary.com/love

United Nations. (2012). Statistics and indicators on women and men. Retrieved October 192014 from http://unstats.un.org/unsd/demographic/products/indwm/

BBC. (2014). Man "killed ex-wife and hid body". Retrieved October 192014 from http://www.bbc.com/news/uk-england-gloucestershire-28409399

Rhodan, M. (2014). Ohio Morgue Worker Admits to Having Sex with 100 Corpses. Retrieved October 192014 from http://time.com/3135722/ohio-morgue-sex-kennethdouglas/

The Trustees of the University of Pennsylvania. (2014). Addiction. Retrieved October 192014 from http://www.med.upenn.edu/psych/addiction.html

Purse, M. (2014). Sociopath. Retrieved October 192014 from http://bipolar.about.com/od/glossarys/g/gl sociopath.htm 
AlleyDog.com. (1998-2003). Collective Unconscious. Retrieved December 92013 from

http://www.alleydog.com/glossary/definition.php?term=Collective\%20Unconscious

Diamond, S. A. (2012). Essential Secrets of Psychotherapy: What is the "Shadow"? Retrieved December 102013 from http://www psychologytodaycom/blog/evildeeds/201204/essential-secrets-psychotherapy-what-is-the -shadow

McClean, P. (2000). The Scientific Method. Retrieved October 192014 from http://www.ndsu.edu/pubweb/ mcclean/plsc431/science/scimeth1.htm 


\section{APPENDIX}

1 - Franke, S. (2003). Space Hardware Acoustic Mitigation. www.colorado.edu/ASEN/.../Space-Hardware-Acoustic-Mitigation.pdf

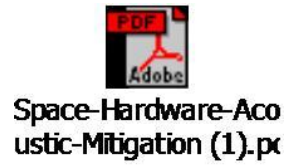

2 - World Health Organization. (2009). Night Noise Guidelines for Europe. www.euro.who.int/ data/assets/pdf file/0017/43316/E92845.pdf

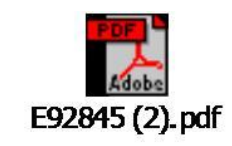

3 - Harvard University. (2000). Calories burned in 30 minutes for people of three different weights. http://www.health.harvard.edu/newsweek/Calories-burned-in-30minutes-of-leisure-and-routine-activities.htm

\section{Calories burned in $\mathbf{3 0}$ minutes for people of three different weights}

(This table was first published to accompany an article in the July 2004 issue of the Harvard Heart Letter. For more information or to order, please go to http://www. health.harvard.edu/heart.)

The table below lists the calories burned by doing dozens of activities listed by category (such as gym activities, training and sports activities, home repair, etc.) for 30 minutes. In each category, activities are listed from least to most calories burned.

\begin{tabular}{|c|c|}
\hline $\begin{array}{l}125 \text { pound } \\
\text { person }\end{array}$ & $\begin{array}{l}155 \text { pound } \\
\text { person }\end{array}$ \\
\hline
\end{tabular}

Gym Activities 
Aerobics: water

Stretching, Hatha Yoga

Calisthenics: moderate

Riders: general (ie., HealthRider)

Aerobics: low impact

Stair Step Machine: general

Teaching aerobics

Weight Lifting: vigorous

Aerobics, Step: low impact

Aerobics: high impact

Bicycling, Stationery: moderate

Rowing, Stationery: moderate

Calisthenics: vigorous

Circuit Training: general

Rowing, Stationery: vigorous

Elliptical Trainer: general

Ski Machine: general

Aerobics, Step: high impact

Bicycling, Stationery: vigorous 
Training and Sport Activities

Billiards

75

93

111

Bowling

90

112

133

Dancing: slow, waltz, foxtrot

90

112

133

Frisbee

90

112

133

Volleyball: non-competitive, general play

90

112

133

Water Volleyball

90

112

133

Archery: non-hunting

105

130

155

Golf: using cart

105

130

155

Hang Gliding

105

130

155

Curling

120

149

178

Gymnastics: general

120

149

178

Horseback Riding: general

120

149

178

Tai Chi

120

149

178

Volleyball: competitive, gymnasium play

120

149

178

Walk: $3.5 \mathrm{mph}(17 \mathrm{~min} / \mathrm{mi})$

120

149

178

Badminton: general

135

167

200

Walk: $4 \mathrm{mph}(15 \mathrm{~min} / \mathrm{mi})$

135

167

200

Kayaking

150

186

222

Skateboarding

150

186

222 
Snorkeling

Softball: general play

Walk: $4.5 \mathrm{mph}(13 \mathrm{~min} / \mathrm{mi})$

Whitewater: rafting, kayaking

Dancing: disco, ballroom, square

Golf: carrying clubs

Dancing: Fast, ballet, twist

Fencing

Hiking: cross-country

Skiing: downhill

Swimming: general

Walk/Jog: jog <10 min.

Water Skiing

Wrestling

Basketball: wheelchair

Race Walking

Ice Skating: general

Racquetball: casual, general

Rollerblade Skating

Scuba or skin diving 
Sledding, luge, toboggan

Soccer: general

Tennis: general

Basketball: playing a game

Bicycling: 12-13.9 mph

Football: touch, flag, general

Hockey: field \& ice

Rock Climbing: rappelling

Running: 5 mph (12 min/mile)

Running: pushing wheelchair, marathon

wheeling

Skiing: cross-country

Snow Shoeing

Swimming: backstroke

Volleyball: beach

Bicycling: BMX or mountain

Boxing: sparring

Football: competitive

Orienteering

Running: $5.2 \mathrm{mph}$ (11.5 min/mile) 
Running: cross-country

Bicycling: 14-15.9 mph

Martial Arts: judo, karate, kickbox

Racquetball: competitive

Rope Jumping

Running: $6 \mathrm{mph}$ (10 min/mile)

Swimming: breaststroke

Swimming: laps, vigorous

Swimming: treading, vigorous

Water Polo

Rock Climbing: ascending

Running: $6.7 \mathrm{mph}$ (9 min/mile)

Swimming: butterfly

Swimming: crawl

Bicycling: 16-19 mph

Handball: general

Running: $7.5 \mathrm{mph}$ (8 min/mile)

Running: $8.6 \mathrm{mph}$ (7 min/mile)

Bicycling: > $20 \mathrm{mph}$

Running: $10 \mathrm{mph}$ (6 min/mile) 
Outdoor Activities

Planting seedlings, shrubs

120

149

178

Raking Lawn

120

149

178

Sacking grass or leaves

120

149

178

Gardening: general

135

167

Mowing Lawn: push, power

135

167

200

Operate Snow Blower: walking

135

167

Plant trees

135

167

Gardening: weeding

139

172

205

Carrying \& stacking wood

150

186

222

Digging, spading dirt

150

186

Laying sod / crushed rock

150

186

222

Mowing Lawn: push, hand

165

205

244

Chopping \& splitting wood

180

223

Shoveling Snow: by hand

180

223

266

Home \& Daily Life Activities

Sleeping

19

23

28

Watching TV

23

28

33

Reading: sitting

34

42

50 
Standing in line

Cooking

Child-care: bathing, feeding, etc.

Food Shopping: with cart

Moving: unpacking

Playing w/kids: moderate effort

Heavy Cleaning: wash car, windows

Child games: hop-scotch, jacks, etc.

Playing w/kids: vigorous effort

Moving: household furniture

Moving: carrying boxes

Home Repair

Auto Repair

Wiring and Plumbing

Carpentry: refinish furniture

Lay or remove carpet/tile

Paint, paper, remodel: inside

Cleaning rain gutters

Hanging storm windows
38

47

56

75

93

111

105

130

155

105

130

155

105

130

155

120

149

178

135

167

200

150

186

150

186

222

180

223

266

210

260

311

90

112

133

90

112

135

167

200

135

167

200

135

167

200

150

186

222

150

186

222 
Paint house: outside

Carpentry: outside

Roofing

Occupational Activities

Computer Work

Light Office Work

Sitting in Meetings

Desk Work

Sitting in Class

Truck Driving: sitting

Bartending/Server

Heavy Equip. Operator

Police Officer

Theater Work

Welding

Carpentry Work

Coaching Sports

Masseur, standing

Construction, general
150

180

223

266

180

223

266

41

51

61

45

56

67

49

60

72

53

65

78

53

65

78

60

74

89

75

93

75

93

111

75

93

111

90

112

90

112

133

105

130

155

120

149

178

120

149

178

165

205

244 
Coal Mining

Horse Grooming

Masonry

Forestry, general

Heavy Tools, not power

Steel Mill: general

Firefighting more information or to order, please go to http://www.health.harvard.edu/heart.)

4 - Pinheiro, M. R. (2014). A New Model for the Human Psyche. Journal of Research in Humanities and Social Sciences. Vol. 2, issue 5, pp. 61-65.

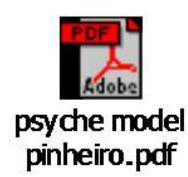

5 - Pinheiro, M. R. (2014). Words for Science. Indian Journal of Applied Research. http://www.theglobaljournals.com/ijar/articles.php? val=NjQ0MQ==\&b1=853\&k=214

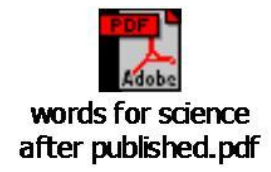

6 - Lopes, A. L. (2011). O que sao mensagens subliminares?

http://mundoestranho.abril.com.br/materia/o-que-sao-mensagens-subliminares 
ABC Research Alert

Vol 3, No 1 (2015) 